\title{
STUDIES OF VOLUME CHANGE
}

\section{IN EXPANSIVE CEMENTS}

\section{FEBRUARY 1965 \\ NO. 3}
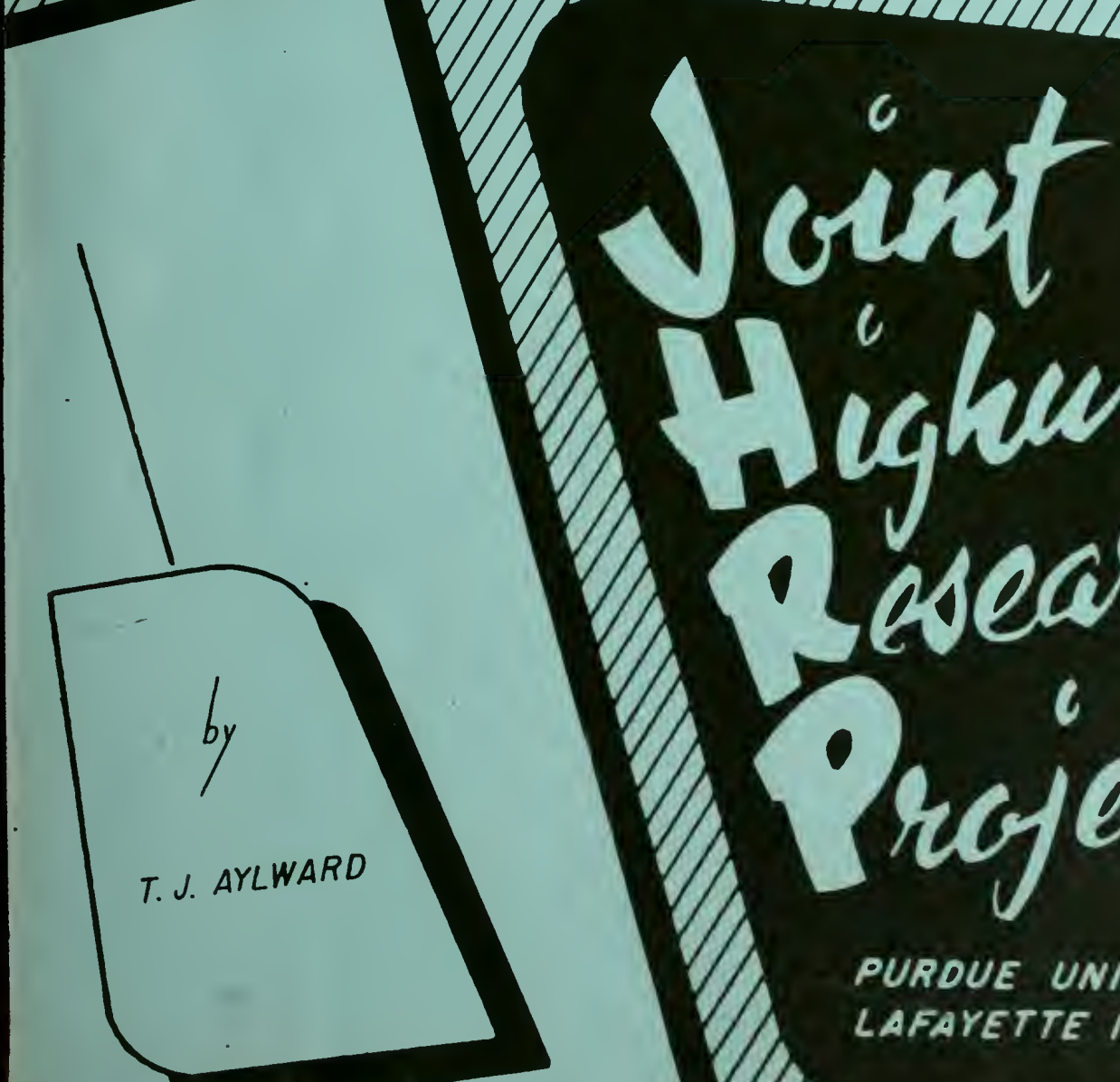

i 

TO: K. B. Woods, Director

Toint Highwry Research Project

February 4, 1965

FROM: H. I. Michael, Associate Director

Joint Highway Research Project

Project: $\mathrm{C}-36-47 \mathrm{~J}$

File: $4-6-10$

A flnal report "Scudies of Volume Changes in Expansive Cements" by Thomes J. Aylkird is attached. The research was conducted under" the direction of Professor W. I. Dolch and the report was also used by $M r$. Aylward in partial fulfillment of the requirements for the MECE degree.

The plar of study for this research was approved by the Board on July 1, 1963. The report Is subritted for the record as completion of the approved research.

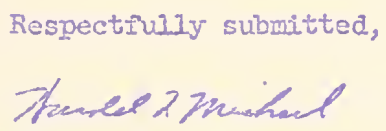

Earola E. Michael, Secrecary

HIM:be

Attachment

\section{Copies:}

F. I. Asbbaucher

J. R. Cooper

H. I. Dolch

H. H. Goetz

H. L. Grecco

F. F. Havey

F. S. H111

G. A. Ieopards

J. F. ReTaverin
F. B. Kendenhal1

R. D. Miles

R. E. Mil1s

J. C. Oppenlander

V. P. Privette

M. B. Scott

J. V. Surthe

E. J. Yoder 
Digitized by the Internet Archive in 2011 with funding from

LYRASIS members and Sloan Foundation; Indiana Department of Transportation 
Final Report

\section{SIUDTES OF VOLUME CHAMCE}

IN IXPAISSTVE CEMIMITS

\section{by}

\section{Thoras J. Aylward}

Gradie.te Assi.stent

\section{Joint Highway Fesearch Project \\ Project: $\quad C-36-475$ \\ Pi1?e: $4-6-10$}

Purảue University

Iafayette, Inaiana

liebruary i, 1505 


\section{ACKLONLEDGENENSS}

The author is deeply grateful to Dr. w. L. Dolch, his major professor, for friendly advice and counsel. His encouragement and academic sponsorship have been greatly appreciated.

Dr. J. L. White and Dr. G. Bailey, both of the Agronomy Department of Purdue University, have been most helpful in every way. Without their counsel and generous allowance of unlimited use of the Department's X-ray diffraction equipment, this work could not have been undertaken.

The author also wishes to thank Professor K. B. Woods, Head of the School of Civil Engineering, and Dr. J. F. McLaughlin, Professor of Civil Engineering, Purdue University, for their friendly counsel and encouragement.

Mr. Robert Nako performed a number of sample preparations and Y-ray analyses.

This study was financed by the State Highway Commission of Indiana through the Advisory Boaro of the Joint Highway Research Project. This support is appreciated. 
Statement of the Problem ................. . 1

Literature Review ... . . . . . . . . . . . . 2 Approach Used in this rork ............... 12

EXPERIMENTAL IORK . . . . . . . . . . . . . 13

Saterials ....................... 13 Sample Freparation . . . . . . . . . . . . . 14 Apparatus and Procedure ................. . . 21 Length Change Ycasurements . . . . . . . . . . 21 Quantitative X-Fay Analysis ............. 22 Weight Change Neasurements ............ 26 Data....................... 26

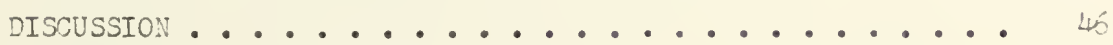

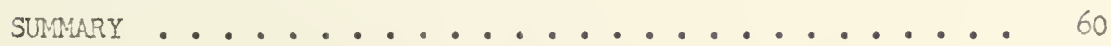

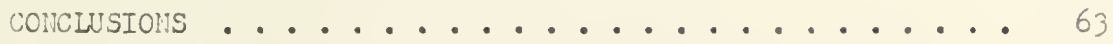
BIBLIOCRAPHY . . . . . . . . . . . . 65

General References . . . . . . . . . . 66 APPEIDIY A . . . . . . . . . . . 68 
LIST OF TABLES

1. Mixtures used in the Testing Program . . . . . . . 15 
1. Portland Cement Lumnite Cement, and Gyosum Ternary Diagram .......................

2. Bar l\%old (Detail) . . . . . . . . . . . 17

3. Assembled Bar Mold ................. 18

4. Bar Mold ...................... 19

5. Powder Mount Equipment . . . . . . . . . . 24

6. Expansion and Ettringite Curves for Mix No. 1-30 . . . 28

7. Expansion and ettringite Curves for Hix No. 2-30 . . . 29

8. Expansion and Ettringite Curves for Mix No. 2-45 . . . 30

9. Expansion and Ettringite Curves for $\mathrm{Mix}$ No. 3-30 . . . 31

10. Expansion and Ettringite Curves for $\mathrm{Mix}$ No. $-45 . . .32$

11. Expansion Curves for Mix No. 3 with $w / c$ ratios of

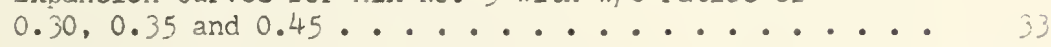

12. Expansion and Ettringite Curves for Kix No. 4-30 . . . 34

1. Expansion and Ettringite Curves for l:ix Vo. $4-45$. . 35

14. Expansion and Ettringite Curves for Mix No. 5- . . . 36

15. Expansion Curves for Mix No. 5-30 Showing Effects of Stripoing ................. 3 ?

16. Expansion and Ettringite Curves for Mix No. 6-30 . . . 38

17. Expansion Curves for Mixes lios. 1-30, 5-30 and 6-30... 39

18. Ixpansion Curves for Vixes ios. 2-30, 3-30 and 4-30... 40

19. Ixpansion Curves for Mixes Nos. 2-45, 3-45 and 4-45 .. 41

20. Weight Change Curves for Mixes lios. 1-30 through 6-30.. 42 
Pigure

Fage

21. Nieight Change Curves for Mixes Nos. 2-45, 3-45 and 4-45. 43

22. Mortar Expansion Curves for Mixes Nos. $1-40,5-40$ and $6-40 \quad 44$

23. Mortar Ixpansion Curves for lizxes lios. 2-40, 3-40 and 4-40 45 


\section{ABSTRADT}

Aylward, Thomas John. M.S.C.E., Purdue University, January 1965. Studies of Volume Change in Exoansive Cements. Major Professor:

J. L. Dolch.

Expansive cements containing proportions of Portland cenent, highalumina cement, and gypsum were prepared. Pastes were made with these mixtures at two different water contents. The pastes were molded into small cylinders which were kept immersed in water. These cylinders were tested to determine their linear expansion, change in weight, and content of tricalcium aluminate trisulfate (ettringite) at various times. The ettringite was determined by quantitative $\mathrm{x}$-ray diffraction. The amount of ettringite, in general, increased very rapidly in the first few hours and then became more or less constant for a similar period. If the mixture contained sufficient gypsum the ettringite contents increased further after either the stripping of the mold or the onset of visiole surface cracking.

The expansion was negligible at first and gradually became progressively greater to the point of disintegration of the sample. Visible surface cracking occurred at about two percent linear expansion, but the specimen remained intact to about ten percent expansion. The weight gain was of the same nature and relative extent as the expansion.

The results indicate that greater expansions are associated with greater amounts of real and potential ettringite and with 
greater water contents, but the association is not simple. Much, but not all, of the relatively large amount of initially-formed ettringite is non-expansive in character. Limitation of water is probably an important factor in limiting the production of ettringite. Ingress of curing water to form additional ètringite is probably an important cause of expansion in these cementitious systems. 


\section{IN TRODU CTION}

\section{Statement of the Problem}

Several cement compositions have been used to produce concrete possessing expansive characteristics. These materials generally have been composed of certain combinations of Portland cement, gypsum, lime, blast-furnace slag, and high-alumina cement (HAC). By varying. the proportions of the constituents it is possible to obtain a material that has no net volume change after shrinkage or one that is expansive and can be used in a self-stressing application.

Understanding of these materials has been hampered because the work performed to date has been largely empirical in a effort to find useful and economical applications. Factors influencing the magnitude and rate of the expansion include chemical composition of the components, fineness of the reacting phases, ratio of water to cementing materials, conditions of curing, and degree of restraint.

The nature of the changes that take place during expansion has been in question from the beginning of the use of expansive cements. The chemical and physical composition of the products formed, the kinetics of their formation, the changes that take place on drying, and the role of water are all topics necessary to the adequate understanding of these cements.

It is generally agreed that the expansion of these materials. whether of the desirable sort expected in anti-shrinkage or self- 
stressing applications or the undesirable sort associated with sulfate attack on concrete, is brought about by the production of ettringite. $3 \mathrm{CaO} \cdot \mathrm{Al}_{2} \mathrm{O}_{3} \cdot 3 \mathrm{CaSO}_{4} \cdot 32 \mathrm{H}_{2} \mathrm{O}$.

The rate of ettringite production during early stages of hydration is presumably an important factor in the volume change characteristics of these cements. The purpose of this investigation was to determine the relationships between the volume change of expansive cement combinations during the early stages of hydration and the production of calcium sulfoaluminate therein.

\section{Literature Review}

This review is an outline of previous work in the field of expansive cements. It is intended to give the reader insight into the mechanisms associated with both detrimental and useful effects of these materials.

In this paper the conventional abbreviations of the chemical formulae of the compounds found in cements will be used. They are as follows: $C=\mathrm{CaO}, \mathrm{S}=\mathrm{SiO}_{2}, \mathrm{~A}=\mathrm{Al}_{2} \mathrm{O}_{3}, \mathrm{~F}=\mathrm{Fe}_{2} \mathrm{O}_{3}, \mathrm{M}=\mathrm{MEO}$, $\mathrm{K}=\mathrm{K}_{2} \mathrm{O}, \mathrm{N}=\mathrm{Na}_{2} \mathrm{O}, \mathrm{H}=\mathrm{H}_{2} \mathrm{O}, \overline{\mathrm{i}}=\mathrm{CO}_{2}, \overline{\mathrm{S}}=\mathrm{SO}_{3}$. In this notation tricalcium silicate, $\mathrm{Ca}_{3} \mathrm{SiO}_{5}$ or $3 \mathrm{CaO} \cdot \mathrm{S}_{2} \mathrm{O}_{2}$, is $\mathrm{C}_{3} \mathrm{~S}$; hydrated tetracalcium aluminate, $4 \mathrm{CaO} \cdot \mathrm{Al}_{2} \mathrm{O}_{3} \cdot 13 \mathrm{H}_{2} \mathrm{O}$, is $\mathrm{C}_{4} \mathrm{AH}_{13}$, etc.

Expansive cements are directly associated with the problem of sulfate unsoundness and its associated excessive volume change. This unsoundness, or slow expansion due to the cement phase in concrete, can be attributed to three causes (1). Crystalline magnesium oxide can cause large expansions when present in excessive amounts in cements. Since MgO reacts slowly with water this expansion 
may not develop until considerable time has elapsed. An excess of hard-burned lime can also cause this same effect. As with magnesium oxide, hard-burned lime reacts slowly with water, causing the concrete to crack after it has thoroughly set. In contrast, soft-burned lime reacts rapidly while the concrete is still plastic and causes no adverse effects.

The third and most common cause of unsoundness is an excess of sulfate. This raterial causes expansion by the formation of hydrated calcium sulfoaluminates, mainly ettringite. Ettringite has a high molecular weight (12.54) and a large water content (44-46\%). It is conmonly found in long, needle-shaped crystals. Calcium sulfate is always present in Portland cement since gypsum is interground with almost all Purtland cement to control the set. This material has no destructive effect under ordinary conditions. The quantity present is small (less than 5\%) and calcium sulfoaluminate is forned mostly while the concrete is still plastic. Difficulty arises when the concrete is exposed to sulfate-bearing waters. The sulfate from these waters then combines with calcium and aluminate constituents present in the cement and may bring about the destructive formation of ettringite. This reaction can be of such magnitude that complete dismption of the concrete will occur.

The problem of sulfate attack was first recognized in Europe in the last century. It was, however, during the 1880's before products were developed to combat the problen. These resembled the present day high alumina cements (2) and were prepared by a process of reacting bauxite, siliceous materials, and lime in a kiln. In 1918 the French 
manufactured the first successful commercial product. Although It was primarily developed for sulfate resistance, it possessed the additional property of rapid hardening. These cements have, however, the undesirable properties of high shrinkage, low strength under hot, wet conditions, high heat evolution and low resistance to alkalis.

It might seem that high alumina cements (HAC) should have low resistance to sulfate action, since they have a high aluminate content and a molar lime to alumina ratio of approximately one. Such cements would therefore have readily available lime and alumina to combine with sulfate and form ettringite. Such, however, is not the case, and high alumina cements have proven their resistance to sulfates in soils, sea water, and industrial liquors. According to Lea (3) various theories have been offered to explain these phenomena. One factor may be an absence of free calcium hydroxide in hydrated HAC in contrast with the situation for Portland cement.

Lafuma (3) has proposed that direct combination of a cement compound in the solid state with a substance in solution leads to expansion, but when the cement compound passes first into solution, reacts, and then precipitates as a solid, no expansion occurs. Lafuma further proposed that calcium sulfoaluminate formation in Portland cement due to the action of sulfate solutions is a reaction of the first type. This explanation is plausible because free calcium hydroxide in hydrated Portland cement paste renders hydrated calcium aluminates insoluble. The hydrated calcium aluminates in high alumina cements are slightly soluble in water when free lime 
is not present and therefore the reaction may be of the second type in such cements.

The primary reason for the resistance to sulfate action of HAC, however, appears to be that the aluminate compounds are simply immune to attack, rather than any difference in the type of reactions. This is substantiated by the fact that chemical analysis of concrete in a sulfate environment shows very little sulfate present (3). This can be explained by the presence of alumina gel which forms a protective film around the hydrates which is not readily dissolved (3). of the three possible mechanisms for producing expansion, only sulfoaluminate will produce a controllable expansion (4) and is the reaction of which advantage is taken in the production of "expansive" cements. In these materials calcium sulfoaluminate, mainly ettringite, is produced during the early stages of hydration while the paste is still plastic (5). The paste can, therefore, undergo expansion without hamful effects.

The useful application of these cements come from the ettringite production after set. By controlling composition, water content, and curing conditions (4) it is possible to obtain a concrete that has an initial expansion about equal to the shrinkage that is nomally associated with concrete on drying, thereby creating a material with a low volume change. It is also possible to obtain an overall expansive material that is suitable as a "self-stressing" agent for prestressed concrete.

Lossier is credited with the comercial development of expansive cements. According to Lafuma (6) the cement of Lossier is made by 
intergrinding $70 \%$ Portland cement clinker with $20 \%$ granulated blast furnace slag and 10\% "calcium sulfoaluminate cement." The last material was obtained by burning a finely-ground mixture of $25 \%$ chalk, 50\% gypsum and 25\% bauxite. The resulting product consisted of about $38 \%$ calcium sulfate, $38 \%$ aluminates, ferrites and aluminoferrites, and 20\% ganma-dicalcium silicate, with smaller amounts of other substances. Lafuma also commented that this sulfoaluminate cement is essentially made up of the sane components as a mixture of HAC and Eypsum. Blast furnace slag is said to act as a stabilizing agent that absorbs excess sulfoaluminate.

This cement, as do all cements using the fomation of ettringite for expansion, requires an abundance of water during the initial curing period. Such French cements have been in use since 1940 and are said to possess sulfate resistance superior to ordinary Portland cement and about the same as that of high-alumina cement. This material has 2. lower heat of hydration than HAC, and does not suffer the loss in strength associated with HAC when cured up to $50^{\circ} \mathrm{C}$. Klein in his review (7) stated that this is not the case, and that these cements have poor resistance to waters containing sulphates. Furthermore, he said that aggregates used should contain no soluble sulfates. These cements nay be difficult to control.

Conmercial expansive cements are now manufactured in the soviet Union, where extensive research has been conducted (5). The Russians have grouped these cements into two general categories - waterproofing and self-stressing expansive cements.

According to Mikhailov (5) the principal uses of waterproofing 
manufactured the first successful commercial product. Although it was primarily developed for sulfate resistance, it possessed the additional property of rapid hardening. These cements have, however, the undesirable properties of high shrinkage, low strength under hot, wet conditions, high heat evolution and low resistance to alkalis.

It might seem that high alumina cements (HAC) should have low resistance to sulfate action, since they have a high aluminate content and a molar lime to alumina ratio of approxdmately one. Such cenents would therefore have readily available lime and alumina to combine with sulfate and form ettringite. Such, however, is not the case, and high alumina cements have proven their resistance to sulfates in soils, sea water, and industrial liquors. According to Lea (3) various theories have been offered to explain these phenomena. One factor may be an absence of free calcium hydroxide in hydrated HAC in contrast with the situation for Portland cement.

Lafuma (3) has proposed that direct combination of a cement compound in the solid state with a substance in solution leads to expansion, but when the cement compound passes first into solution, reacts, and then precipitates as a solid, no expansion occurs. Lafuma further proposed that calcium sulfoaluminate fornation in Portland cement due to the action of sulfate solutions is a reaction of the first type. This explanation is plausible because free calcium hydroxide in hydrated Portland cement paste renders hydrated calcium aluminates insoluble. The hydrated calcium aluminates in high alumina cements are slightly soluble in water when free lime 
expansive cements are for caulking, patching, and other repair work where watertightness must be assured.

It is stated that layers as little as $3.5 \mathrm{~cm}$. thick can be placed directly on damp surfaces and will promptly stop water seepage. The waterproofing quality of these cements may be due to the disruptive effect of ettringite growth that effectively destroys the natural pore system of the concrete. These cements were first developed in 1942, and are made by dry grinding artificial hydrocalumite, gypsum, and $\mathrm{HAC}$. The first compound, artificial hydrocalumite $\left(\mathrm{C}_{4} \mathrm{AH}_{13}\right)$ was obtained by joint hydration of high-alumina cement and Iime, followed by drying and grinding. It should be noted that this synthesis of $\mathrm{C}_{4} \mathrm{AH}_{13}$ could not be repeated in the present study using HAC manufactured in the United States. Stoichiometric amounts of Lumnite HAC (assumed mostly $\mathrm{CA}$ ) and lime were reacted, and the product was oven dried and ground. The resulting product, when examined by X-ray analysis, contained a large amount of free lime and some $\mathrm{C}_{3} \mathrm{AH}_{6}$ and $\mathrm{C}_{4} \mathrm{AH}_{13}$

The expansion process of these cements is caused by rapid formation of calciur. sulfoaluminate during the early stages of hydration, which levels off after the paste is set. The expansion after set is at a rate that compensates for normal shrinkage. According to Mikhalov (5) these cements are rapid-setting, reach a high strength in several hours and withstand high hydrostatic pressure without any signs of water transmission. He also stated that the degree of expansion is largely regulated by a change in the proportions of the components. 
Waterproofing but non-expansive cements are another type in the general class that is now manufactured in the U.S.S.R. This material has a lower gypsum and higher $\mathrm{C}_{4} \mathrm{AH}_{13}$ content than the expansive type. According to Mikhailov' (5) this material gives little expansion in humid storage and is characterized by rapid seting and hardening, instantaneous watertightness, and relatively low strength.

Self-stressing cements were more recently developed in the Soviet Union. These cements are composed of finely-ground Portland cement clinker, high-alumina cement, and gypsum. Again according to Mikhailov (5), this material, cured under the proper conditions, acquires sufficlent strength and expands against the restraint of the reinforcement and thereby creates a self-stressed condition. Any Portland cement in amounts of from 60 to $70 \%$ to which high alunina cement and gypsum have been added in the proper proportions is said to make self-stressed cement. As in all expansive cement, the watercement ratio and curing conditions are important. These cements are made with 25 to $30 \%$ water and cured at elevated temperatures to accelerate sulfoaluminate formation and hydration of the silicate components. They therefore have a higher strength with less expansion than samples cured in the usual way.

In the United States Klein and Torxell (7) developed an expansive cenent suitable to prestress concrete containing high strength steel. This material consists essentially of a blend of Portland cement of high $\mathrm{C}_{3} \mathrm{~S}$ and low $\mathrm{C}_{3} \mathrm{~A}$ content with an expansive component obtained by grinding a clinker of calcium sulfoaluminate composition. The latter is produced by burning calcite, gypsum and baúdte. 
Klein, Karby and Polivka (8) have investigated these materials and stated that free lime and low water-cenent ratio are essential in the initial formation of ettringite. These factors insure that the solution will remain supersaturated during the initial stages of ettringite production and expansion. Klein, Karby and Polivka in this same study investigated Klein's expansive cement under various conditions of restraint. They found that this material can produce selfstress when properly restrained, even with the reduction in strength accompanying expansion.

Klein and Lin (9) have published a recent article in which they reported tests of pressure pipes and one- and two-way slabs made with Klein's expansive admixtures. They conclude that structural behavior of these materials can generally be predicted by the elastic and plastic theories of structural analysis. These cements, as well as the French and Soviet expansive cement are subject to aeration and must be packaged in moisture-proof bags to prevent deterioration of their useful properties.

Monfore (4) recently reported investigations of certain properties of expansive cements composed of portland cement, gypsum and HAC. These compositions are of the general type of the Russian "selfstressing" cements. In Monfore's work, mortars were used to evaluate effects of composition, water-cement ratio, curing time and temperature of curing water on strength, free expansion, shrinkage and development of stress in restrained specimens. The greater the rate of expansion, the greater was the maximum expansion. Expansion decreased as the specimen cross-section increased. He also stated 
that mixes with high gypsum and HAC contents had a low expansion when cured in water at $160^{\circ} \mathrm{F}$, presumably because most calcium sulfoaluminate was produced while the material was still plastic. Ixpansion decreased with increasing water-cement ratio between 0.25 and 0.30 . Bars cured at $73^{\circ} \mathrm{F}$ showed a substantially higher expansion than did bars cured at $170^{\circ} \mathrm{F}$ for 24 hours and then cured further at $73^{\circ} \mathrm{F}$. Bars made with 4-6\% gypsum and 4-10\% Lumnite HAC had relatively the same shrinkage after the maximum expansion was reached, even though this expansion varied from 0.12 to $1.88 \%$. The shrinkage was comparable to that of mortar bars made from ordinary Type I Portland cement under the same curing conditions. Tests were also conducted on the selfstressing abilities of these materials, and it was found that the stress built up to avalue of $350 \mathrm{psi}$ at 88 days and then fell off to 150 psi after two years. This result indicates that the material undergoes creep.

Various other investigations have been conducted in the field of expansive cements, mainly by Russian workers. Owing to the language barrier and difficulty in obtaining literature, only a brief outIne of these works is presented from information obtained from Chemical Abstracts.

Kozielski (10) described four Russian high-expansive cements and their methods of manufacture. The first class has been previously discussed, and are known as waterprcofing expansive cements. He describes another cement made by adding $30 \%$ gypsum to high-alumina cement composed mainly of $\mathrm{CA}$ and $\mathrm{C}_{12} \mathrm{~A}_{7}$. This mixture is said to have less tendency to form cracks. Another composition is described 
composed of 70 to $80 \%$ blast-furnage slag, 8 to $9 \%$ Portland clinker, 3 to 5\% HAC and 5 to $15 \%$ hemihydrate. This cement is said to be especially suited for pressure grouting and oil wells. A fourth cement is made by burning at 800 to $900^{\circ} \mathrm{C}$ a mixture composed of 3 to $7 \%$ dolomite, $31 \%$ lime, and $21 \%$ magnesium oxide, and adding this material to self-stressing or waterproofing expansive cements. This material is said to have the advantage of ease in application and of low cost.

Skramtaev and Kravchenko (11) conducted a 5 year-long testing program on gypsum-alumina expanding cements. This paper in noteworthy since they stated that a 1:2 mortar would withstand 130 freezing cycles while a $1: 2: 5$ concrete could withstand 170 and retain more than $82 \%$ of the original strength. They also stated that corrosion of the reinforcing bars, produced in the first 3 to 7 days, did not increase on further storage for five years.

Budnikov and Kozjriva (12) described a cement that expands without the formation of calcium sulfoaluminate. This material is prepared by adding calcinized dolomite (containing MgO) as the expanding agent to hydraulic cement. Guizburg and Veseseojug (13) made tests to determine the effects of water-cement ratio, storage conditions and additives on cenent mixes made with gypsum and expanding cements. Pichedlov-Petrosyan and Filatov (14) described a cement made by adding $0.01 \%$ aluminum powder and a small amount of sulfite waste to ordinary Portland cement, with the sulfite waste serving as a retarder of the lime-aluminia reaction. This material is said to give a small amount of swelling but has a low initial strength. The author also described 
a similar cement, but with the addition of $2 \%$ calcium chloride and 2\% aluminum sulfate.

Budnikov (15) patented an expansive cement made with a hydraulic binder and an expanding material composed of clay or kaolin burned at $700-800^{\circ} \mathrm{C}$. Iime and Portland cement. The dry ingredients were then mixed with water, and after hardening and drying, ground and mixed with an equal amount of hemihydrate.

\section{Aooroach Used in this Work}

Pastes and mortars made with gypsum. Type I Portland cement and Lumnite HAC were used in this work. Length changes were measured by means of a micrometer caliper on small cylindrical bars. X-ray diffraction samples were obtained at various times from paste bars identical to those used for length change determinations. A quantitative X-ray analysis was performed on these samples, using a quartz internal standard, to determine the amount of ettringite formed. Weight changes were also determined on similarly prepared paste bars. 


\section{EXPERIMENTAL WORK}

\section{Materials}

Type I Portland cement (laboratory designation 317), Lumnite high alumina cement, and reagent grade calcium sulfate dihydrate (EJpsum) were used as the major constituents of the samples. The chemical analyses of the Portland and Iumite cements are given in Appendix A. The gypsum was finely ground to break up lumps that were originally present in the material. Graded Ottawa sand (ASTM: Designation: ( 109) was used for all mortars.

Synthetic ettringite was used to prepare a calibration curve for the determination of the amounts of this material in the hydrated paste samples by quantitative $X-$ ray diffraction analysis. Ettringite was prepared by a method similar to that described by Lea and Desch (17). Stoichiometric amounts of reagent aluminum sulfate and calcium hydroxide were added to a large excess of water. The solution was rolled in a glass bottle on a roller mill for approximately four hours. It was then allowed to stand for twenty-four hours, was filtered, and the residue was dried with acetone and ether. At the time the calibration curve was determined an ignition loss was performed on the ettringite. This time was approximately three weeks after the material was prepared. It was found that the ettringite contained 28 moles of water rather than the 32 of the usual formula. Fresh ettringite was prepared that had an ignition loss indicating 32 moles of water. Various points on the standard calibration curve were checked with this fresh material, and it was found that there was no change in the curve. 
Fine quartz used as an internal standard was prepared by a sedimentation process. An amount of finely ground silica was allowed to settle in a large volume of water for thirty-three minutes. At this time the top four and one half inches of solution was drawn off. This material had a theoretical maximum size of 8.3 microns as determined by the usual Stokes law calculation. The suspension was evaporated to dryness, and the residue was ground to break up loosely held aggregates that formed during heating.

\section{Samole Preparation}

Various proportions of Portland cement, Lumnite cement, and gypsun were used to make paste and mortar bars. These bars were then investigated to determine their expansive characteristics. The compositions used and the numbers assigned thereto are shown in Figure 1 and Table 1.

The dry materials for paste samples were mixed for one minute with a laboratory stirrer. Distilled water was then added, and the paste was mixed by hand for one minute and by the stirrer for an additional minute. The paste was then placed in the molds and vibrated on a vibrating table for aporoximately 30 seconds to remove entrapped air. Molds were placed directly in water which was at a temperature of $20^{\circ} \mathrm{C} \pm 2^{\circ} \mathrm{C}$.

Kolds used to make specimens are shown in Figures 2, 3 and 4, and consisted essentially of three parts. A snall cylinder of plastic was split longitudinally into two equal sections and pinned at two opposite corners to promote stability. The two sections were then held together by means of an adjustable hose clamp. The bottom disk 


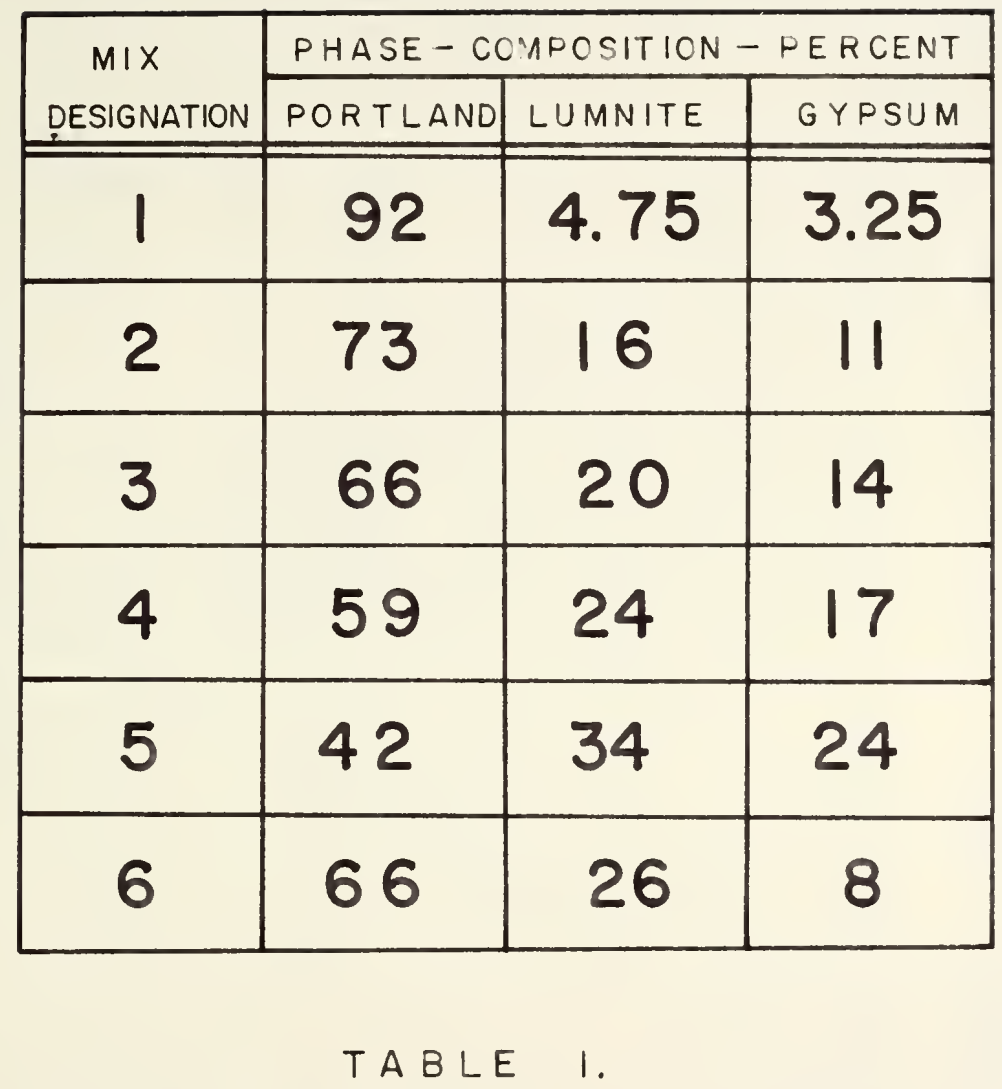

MIXES USED IN THE TEŚting PROGRAM. 


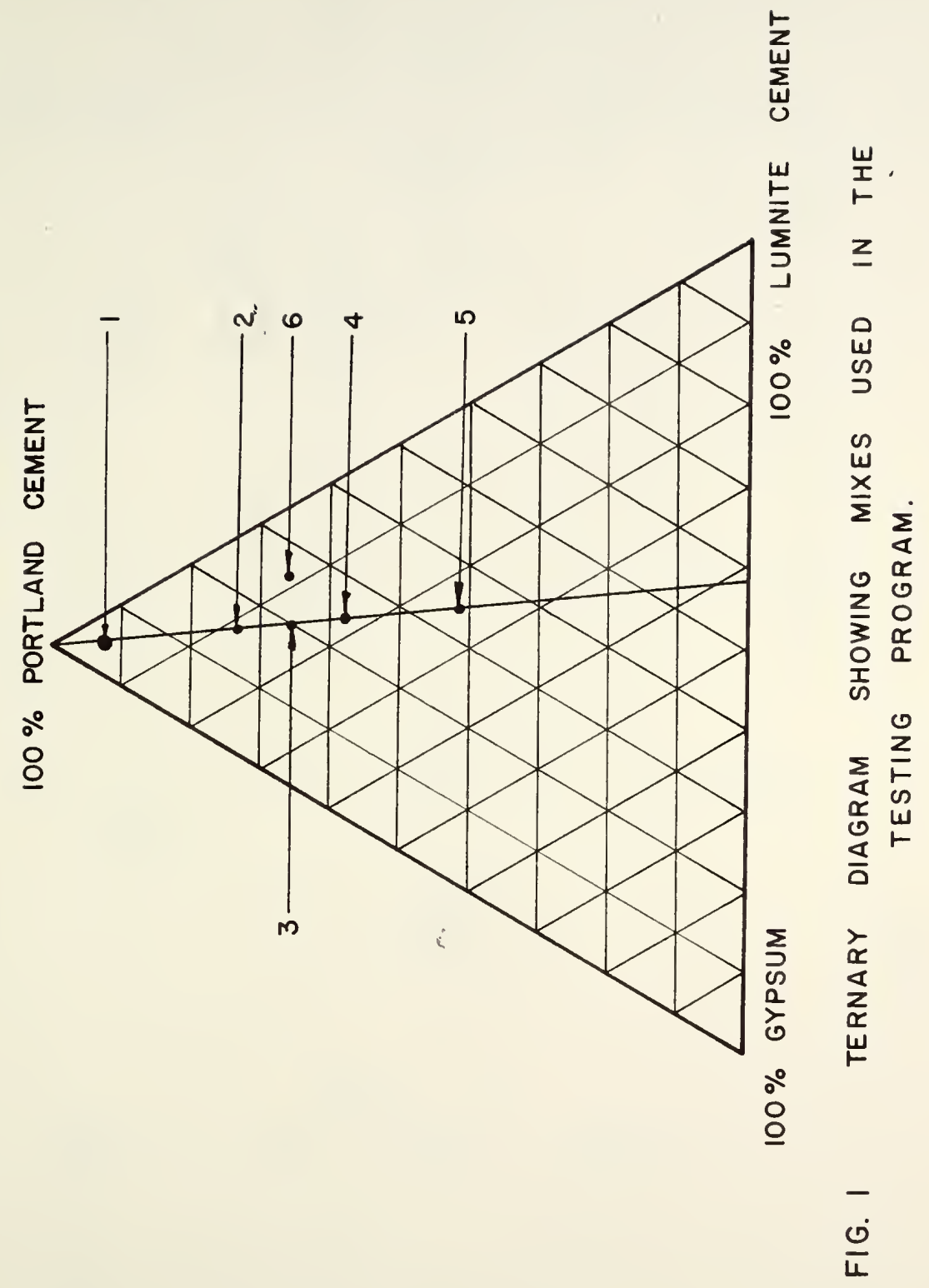




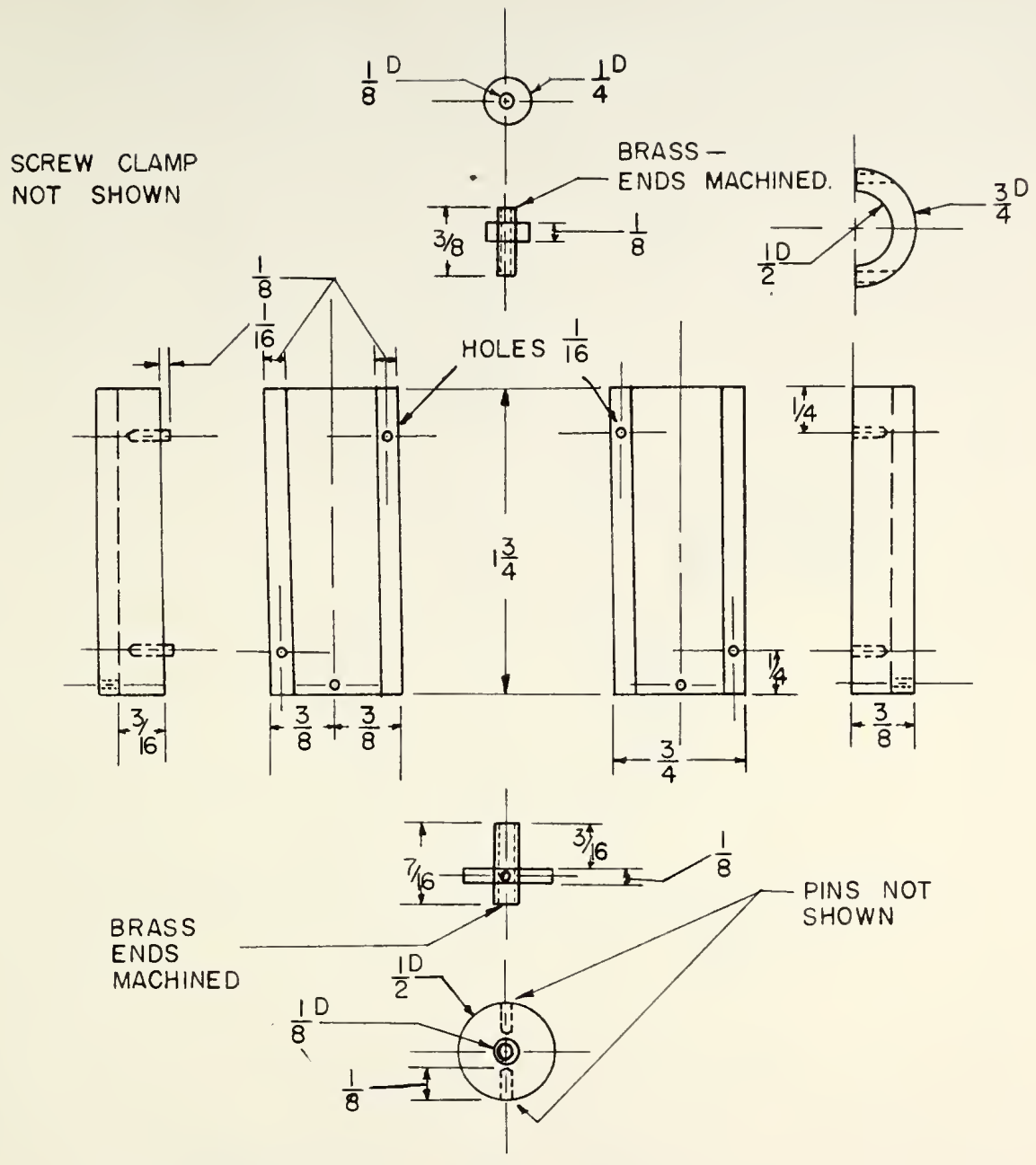

SCALE I:I

$\begin{array}{llll}\text { FIG. } 2 & \text { BAR MOLD } & \text { (DETAIL) }\end{array}$ 
18

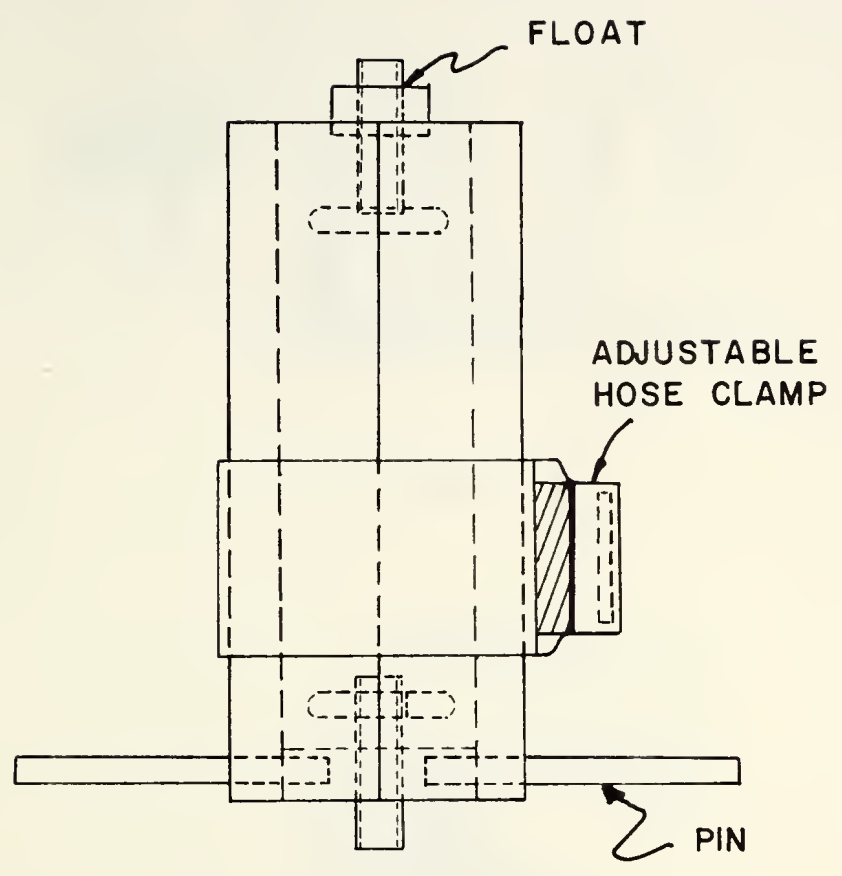

SCALE $2: 1$

AS SEMBLED BAR MOLD

FIG. 3 

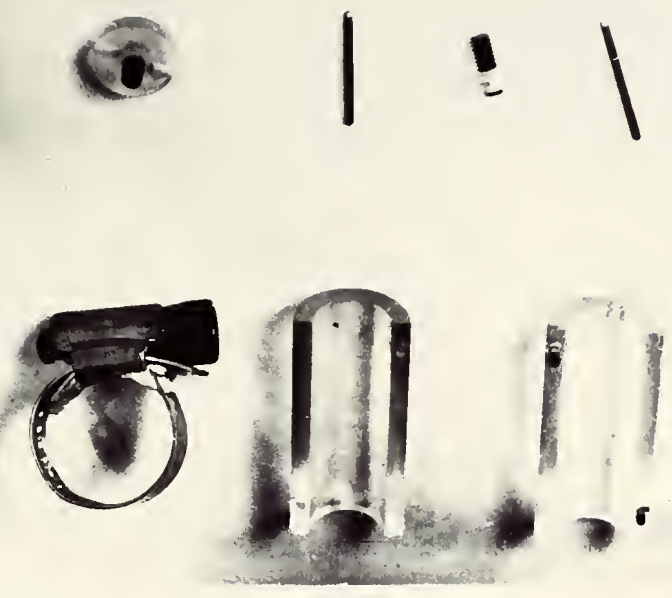

Component Parts

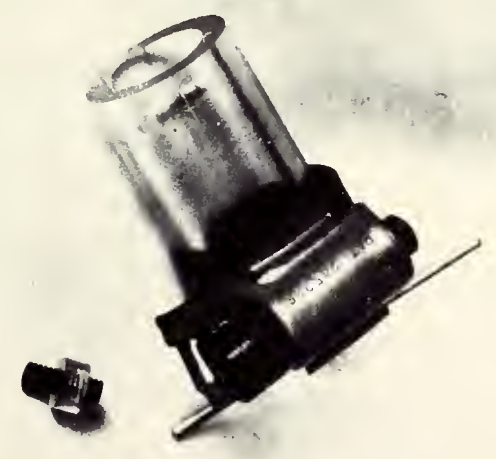

Assembled

Figure 4. Bar Mold 
was machined to fit loosely inside the split cylinder. The disk was drilled and tapped in the center and a 1/8-inch diameter threaded brass stud was inserted so that approximately $3 / 16$ of an inch of the stud would be surrounded by paste or mortar. The other end provided a point for length change measurements. The bottom disk was held in place by two steel pins that were inserted through the surrounding cylinder into either side of the disk. The split cylinders and bottom disks were consecutively numbered for aligment and recording purposes. The top section was designed to "float" on the sample in the mold and thereby permit measurement of length changes. The "float" consisted of a 1/4-inch dianeter and 1/8-inch thick disk that was drillod in the center. Through this hold a $1 / 8$-inch diameter threaded brass stud was inserted. Approximately 1/8-inch of the stud extended into the mix while $1 / 16$-inch remained above the disk to provide the other point for measuring the length changes. All stud ends wore machined flat for measurement purposes. Unless otherwise stated all parts of the mold were made of clear plexiglass. The pins were lubricated for ease in the stripping operation.

A total of eleven molds were prepared for each paste composition. Two paste bars were prepared for length change measurements, two for weight measurements, five for X-ray analysis, and two nortar bars for length change measurements. For X-ray and weight change samples, the top "Ioating" section was not inserted.

Nortar samples were prepared in the same way except that sand was added after the fine materials had been blended. After sand (twice the weight of the fine materials) was added the total mix was again blended for one minute. Mortar samples had a w/c ratio of 0.40 . 
At various times during the course of hydration, portions of the paste bars were taken for X-ray analysis. The paste was ground under acetone in an agate mortar to terminate hydration, and was then air dried overnight. Twenty-five percent of fine silica by weight of the dry paste was then added. It was observed that the silica tended to form lumps. To break up these lunps and to facilitate thorough mixing the mixture of dried paste and s1lica was ground under acetone in a small glass jar on a roller mill using stainless steel balls.

The samples were then air dried overnight, ground with a mortar and pestle and bottled.

The samples used to prepare the X-ray analysis calibration curve consisted of various known proportions of ettringite, fine quartz as an internal standard, and Lumnite conent as a diluent. Various proportions of the materials were weighed out and ground and mixed for approximately one-half hour in the roller mill, as was previously described.

\section{Apparatus and Procedure}

\section{Length Change Veasurements}

All tests were made on small cylindrical bars. Relatively snall specinens were made to obtain as rapid an equilibrium with ambient conditions as possible.

After the mix had been placed in the nold the top floating section was inserted, centered and "set." The initial length readings were taken during this "setting" operation. All length readings were taken by means of a friction thimble micrometer caliper cali- 
brated to \pm 0.0001 of an inch. Since the specimens were about 2 in long the accuracy of strain values is about $0.01 \%$. The initial "setting" of the "float" was done by placing the micrometer so that the anvil was resting directly against the end of the lower stud while the micrometer spindle was close to the upper ("float") stud, and then adjusting the micrometer until there was no rebound of the float when the micrometer spindle was backed off. This reading was taken as the zero point of strain. After the initial readings were talsen all samples were placed in a nearly vertical position in water to hydrate.

:lost samples were stripped after 16 hours of hydration. This operation consisted of removing the hose clamp, pulling the two pins that stabilized the bottom disk and prying apart the split cylinder. The bottom disk and top "float" remained with the bar.

The bars were marked so that all readings would be taken with the bars in the same position. Length measurements were then taken at the time the bars were stripped and at intervals until the bars vere completely disrupted or until length changes ceased.

\section{Quantitative X-Ray Analysis}

The amount of ettringite in the paste samples was determined by quantitative X-ray diffraction. The general procedure was to mix the sample with a known amount of finely-divided quartz, to determine the ratio of the X-ray diffraction counts for the $9.73 \AA$ ettringite peak and the $3.34 \AA$ ouartz peak. The amount of ettringite present was then determined by reference to a calibration curve that 
had been prepared using known amounts of synthetic ettringite, quartz and HAC. The HAC was chosen as a diluent for the calibration samples because its X-ray absorption approximates that of the pastes that were the other samples.

Analyses were performed on a GE XRD-5 diffractometer using Cu-Ka radiation at $40 \mathrm{kV}$ and $16 \mathrm{ma}$. One-degree beam and 0.2 -degree detector slits were used. The data vere taken, for the nost part, on a cumulative printer.

Powder mounts were made by a slight variation of the NcCreery method (16), which minimizes preferred orientation. The equipment used is shown in Figure 5. The sample holder was a small plate of alurinum $11 / 2 \times 1 \times 1 / 8$-inch in size with a 9/16-inch hold drilled through the center. The cell-filling procedure was as follows:

(1) A piece of typing paper the size of the plate was placed on the plate and then a glass microscope slide was placed over the paper. The assembly was bound firmly at each end with scotch tape.

(2) An excess of the powdered sample was placed into the cavity in the plate.

(3) The powder was tapped gently with the point of a spatula in two directions perpendicular to each other.

(4) This procedure was repeated with the blade of the spatula across the top of the cavity in the plate.

(5) Excess powder was removed to leave approximately $1 / 16$ inch of material above the top of the cavity. A glass slide was then pressed against the sample to compact the naterial. 


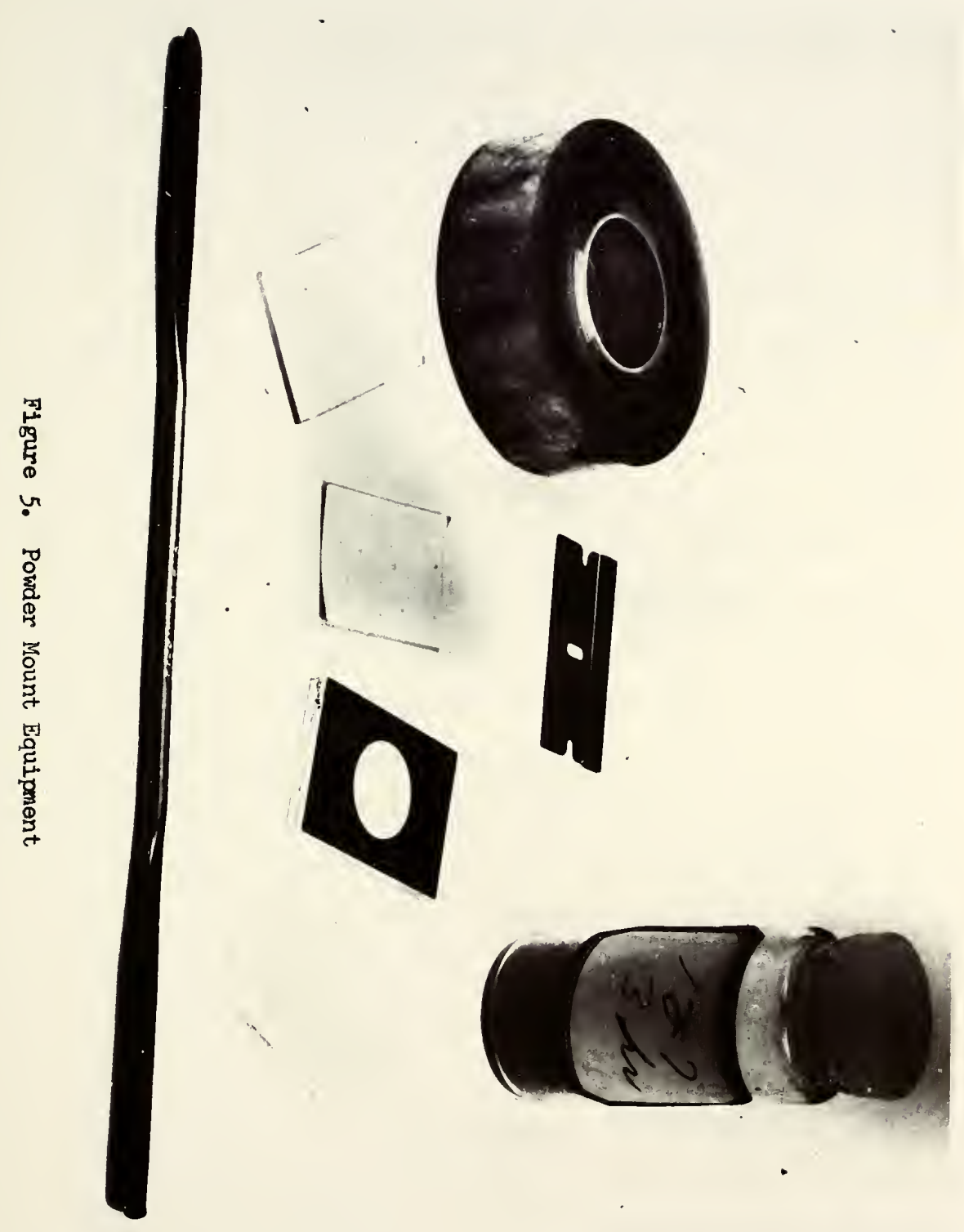


(6) Yore sample was added, and steps 4 and 5 were repeated.

(7) After the last compaction the slide used was taped to the plate and the exposed sample.

(8) The tape holding the other slide and the piece of paper was tinen cut, and the face of the sample was exposed. The result was a flat powder face with a minimum of preferred orientation.

A minimum of five powder mounts were made and X-rayed for each sample. Sach mount was $\mathrm{X}$-rayed with the goniometer scanning speed set at 0.2 degree 20 per minute while recording the pattern on the recorder and the counts on the digital printer. The following procedure was used: the goniometer was set at $8.4^{\circ}, 20$ and a 100 -second count was taken to determine the background. The goniometer then was allowed to travel through one degree, $2 \theta$, and both the background counts and counts due to ettringite were recorded. The goniometer was then set at $9.4^{\circ}$ and another 100 second count was taken. From the two 100 second counts 1 t was possible accurately to determine the average background intensity. This value was subtracted from the total counts obtained to get the counts due to ettringite alone. The same procedure was used to determine the counts from the quartz internal standard by allowing the goniometer to travel from $26.0^{\circ}$ to $27.0^{\circ} 2 \theta$ and taking 100 second counts at the two end points. The ratio $I_{E} / I_{Q}$, the intensity of the ettringite peak to that to the quartz peak, was then calculated.

The ratio, $I_{E} / I_{Q}$ was determined for each of the five powder mounts. The average value of the ratio and the standard deviation were computed. These data were statistically analyzed by standard 
methods $(18,19)$ to determine readings not belonging to the population. The average values thus obtained were then multiplied by the appropriate factor determined from the standard calibration curve to determine the amount of ettringite in the paste (20).

\section{Weight Change Measurements}

Weight change data were obtained from paste bars prepared and cured in the same way as those used for X-ray analysis and for strain measurements. The bars were surface dried with a damp cloth and weighed on an analytical balance. The first weight was measured just after stripping the molds. The zero-time weight was extrapolated from a plot of weight vs. time.

\section{Data}

The proportions of the various mixtures of Portland cement, HAC and gyosum are shown in Table 1 and Figure 1. - In the data and figures to follow the inixtures are designated by prefix numbers 1,2 , etc. and the water to "cement" or, rather, fine materials ratio is designated by the following number. For example, the designation 3-30 means nix proportions No. 3, as shown in Figure 9 , and a w/c ratio of 0.30 . Designation $2-45$ means $\mathrm{mix}$ proportions No. 2 and $\mathrm{w} / \mathrm{c}=0.45$, etc. In what follows w/c refers to the ratio by weight of the mix water finely divided solids, i.e. the sum of the Portland cement, HAC, and gypsum.

Expansion and ettringite content data were obtained for all 6 mixes with a $w / c=0.30$. These data are given in Figures $6,7,9$, 12, 14 and 16. Additional data were obtained for mixture Nos. 2, 3 
and 4 made with $w / c=0.45$; these data are shown in Figures 8,10 and 13. Flgure 11 shows expansion strain data obtained for mix No. 3 with $w / c$ of $0.30,0.35$ and 0.45 , respectively. Figure 15 shows additional data for mix No. 5; expansion curves are shown for paste bars stripped after both four and sixteen hours of hydration. Figures 17, 18 and 19 show summary strain data for both water contents. Neight change data were obtained for the paste bars. Data obtained for mixtures Nos. 1-6 made with a w/c of 0.30 are presented in Figure 20. Figure 21 shows the same data obtained for mixes Nos. 2, 3 and 4 made with 45 percent water. Two to one (graded Ottawa sand to "cement") mortars were prepared for all six mixes with a w/C ratio of 0.40 . Expansion data obtained from these mortar bars are presented in Figures 22 and 23. 


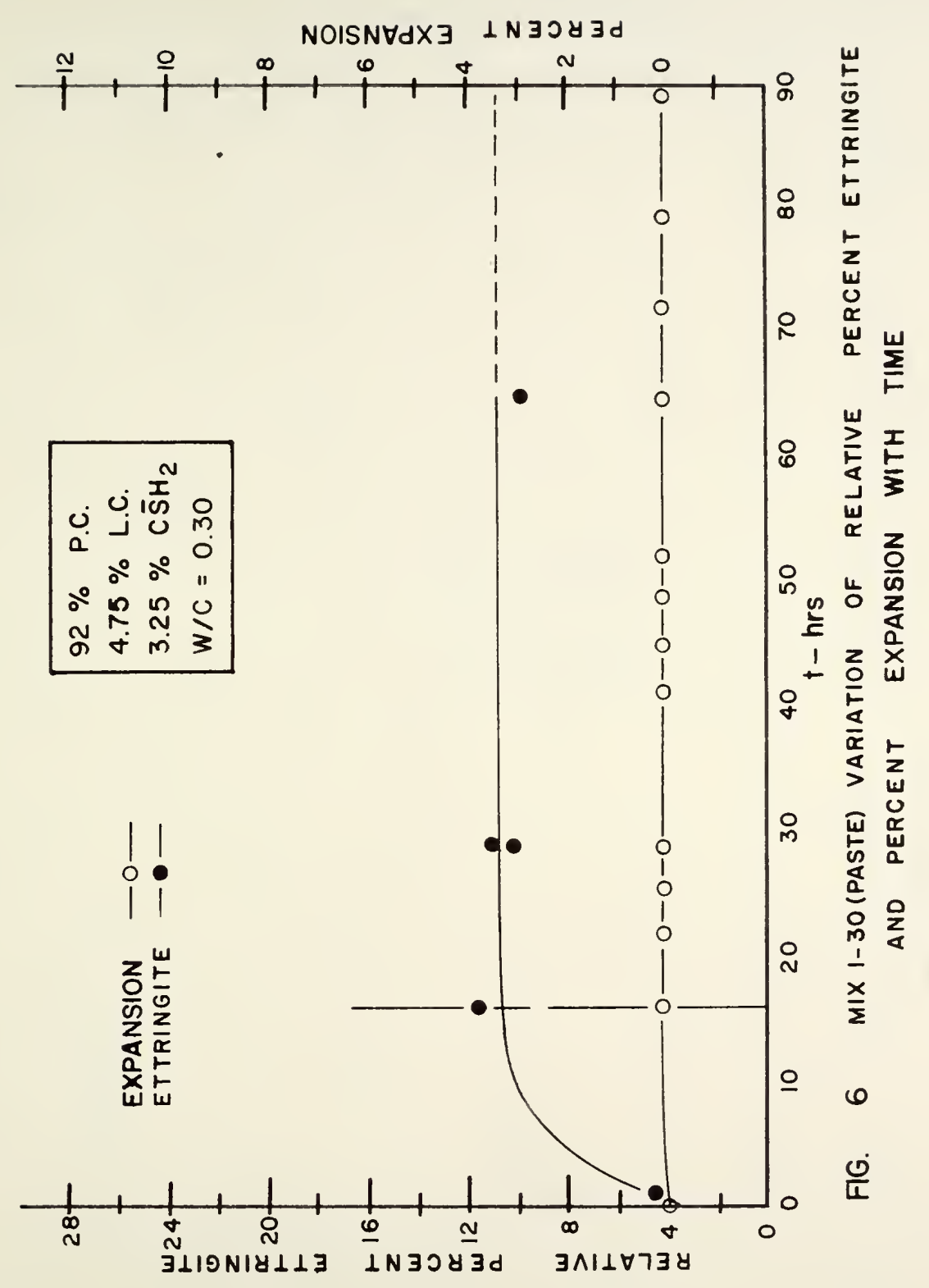




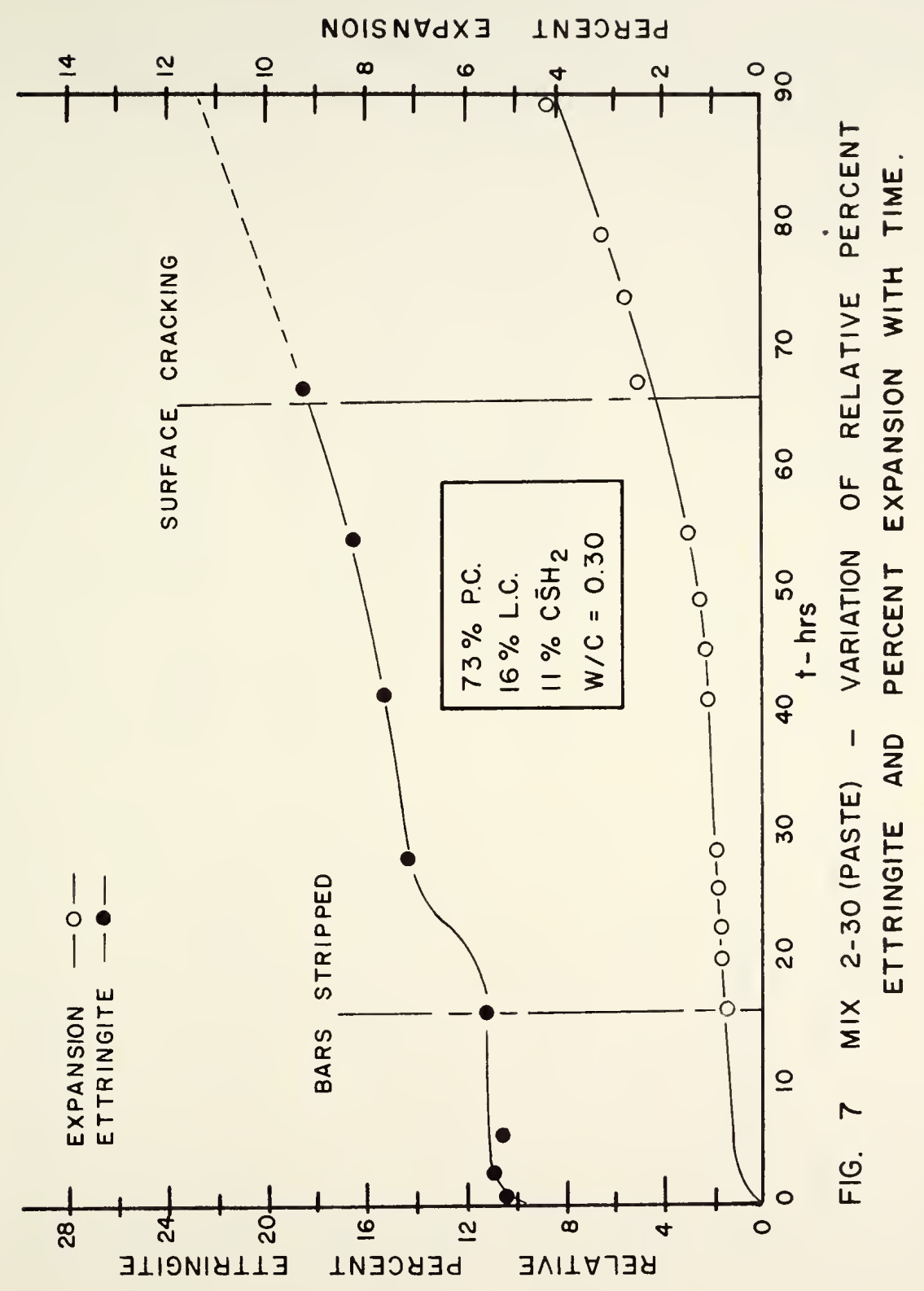




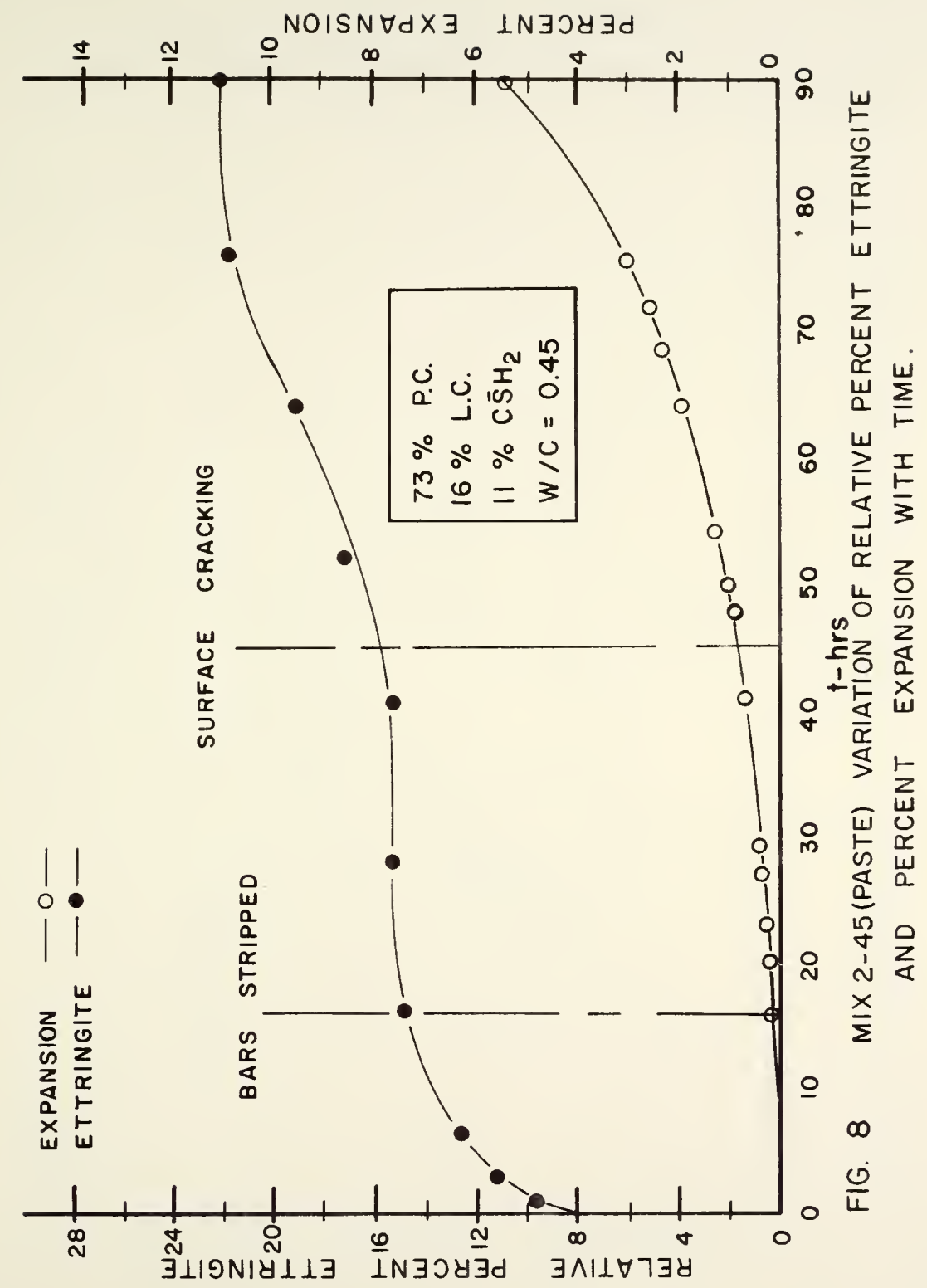




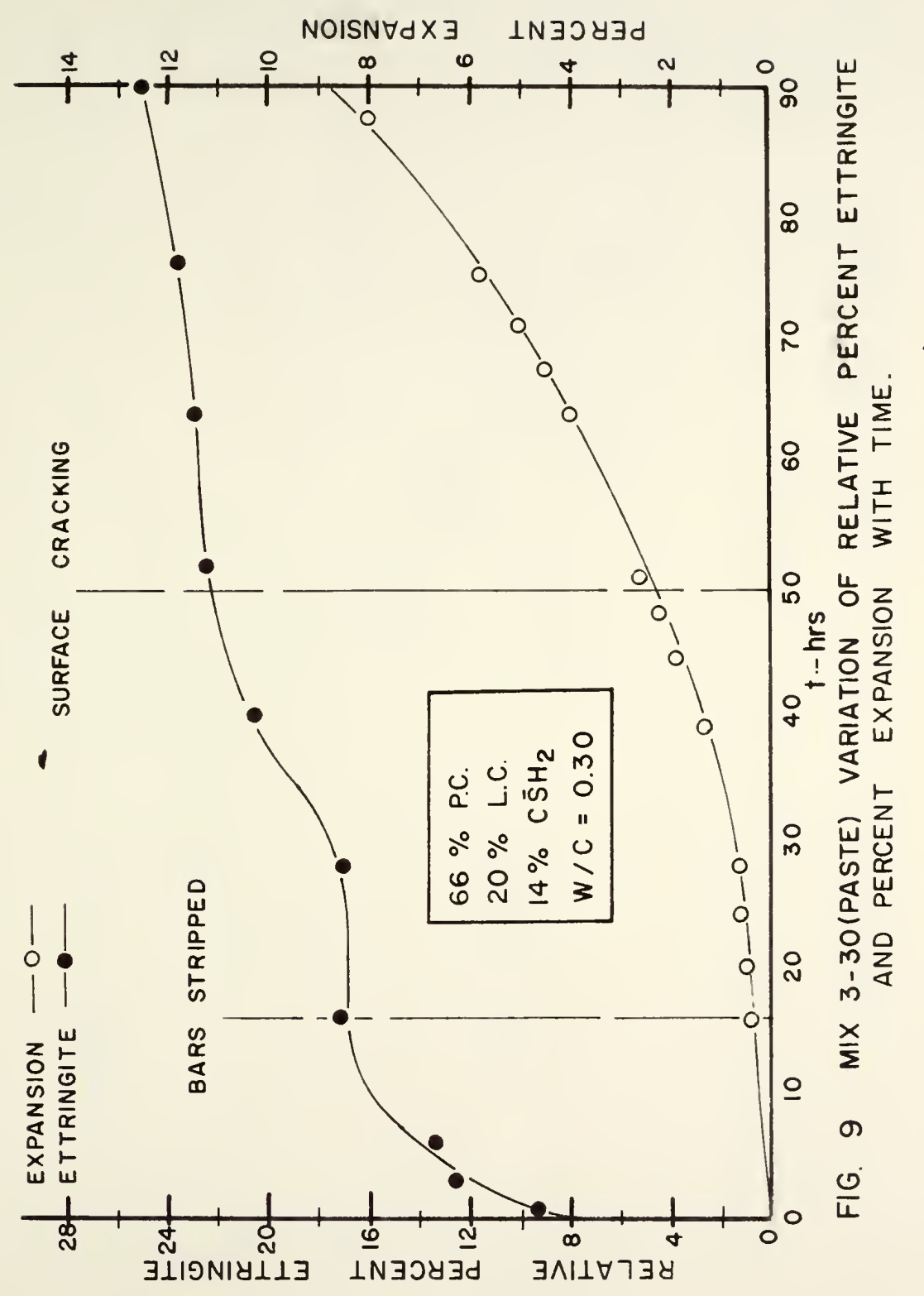




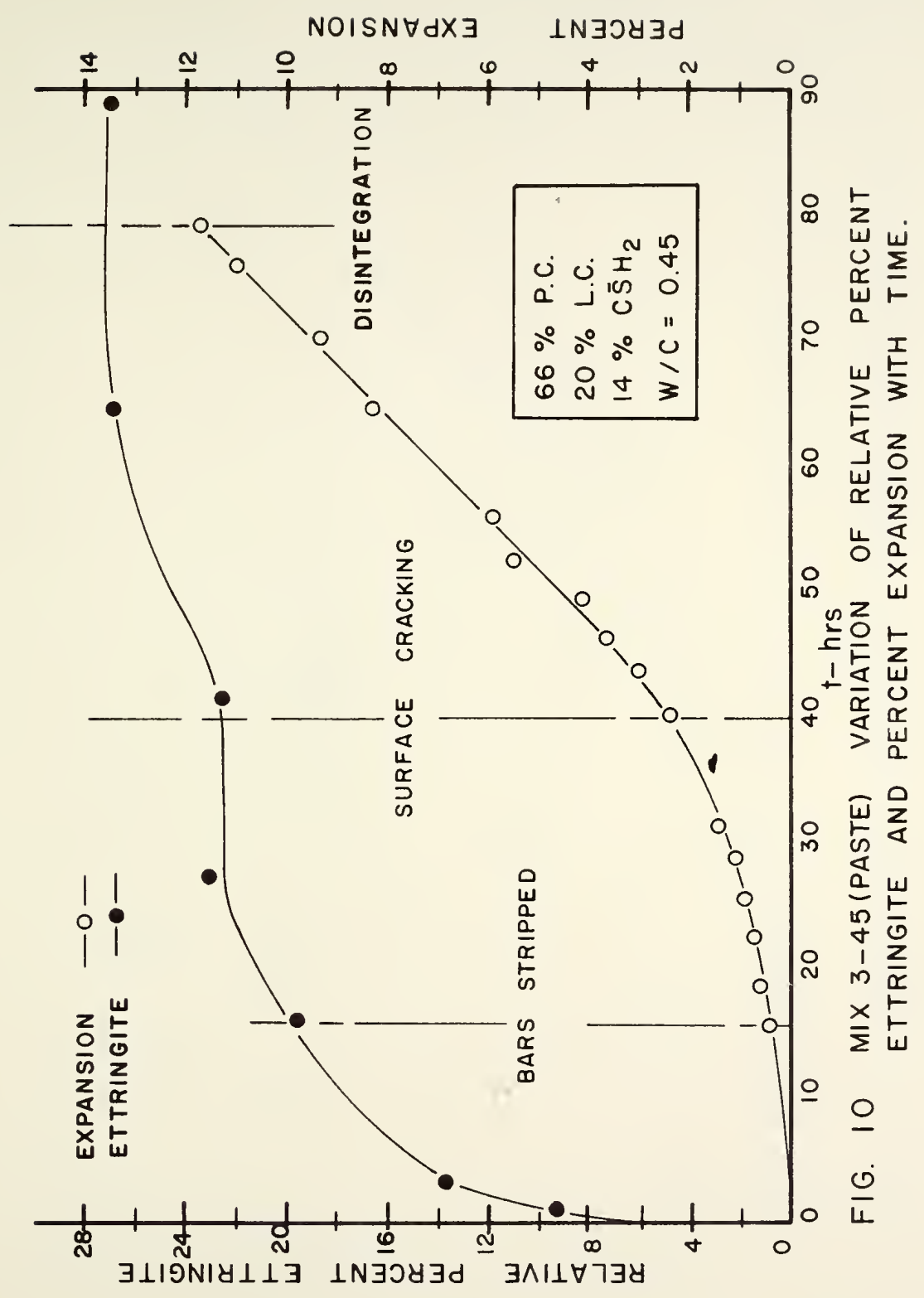




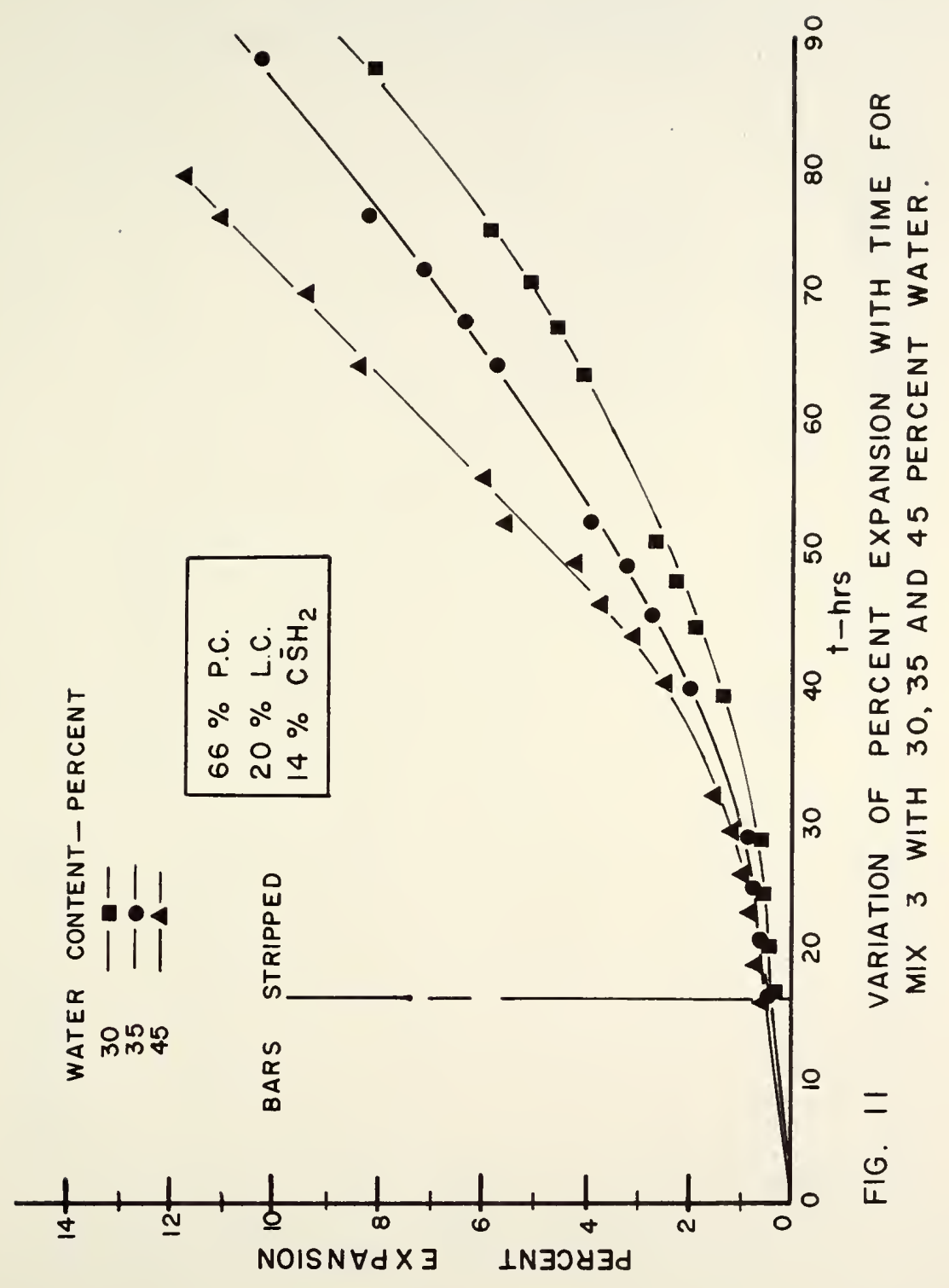




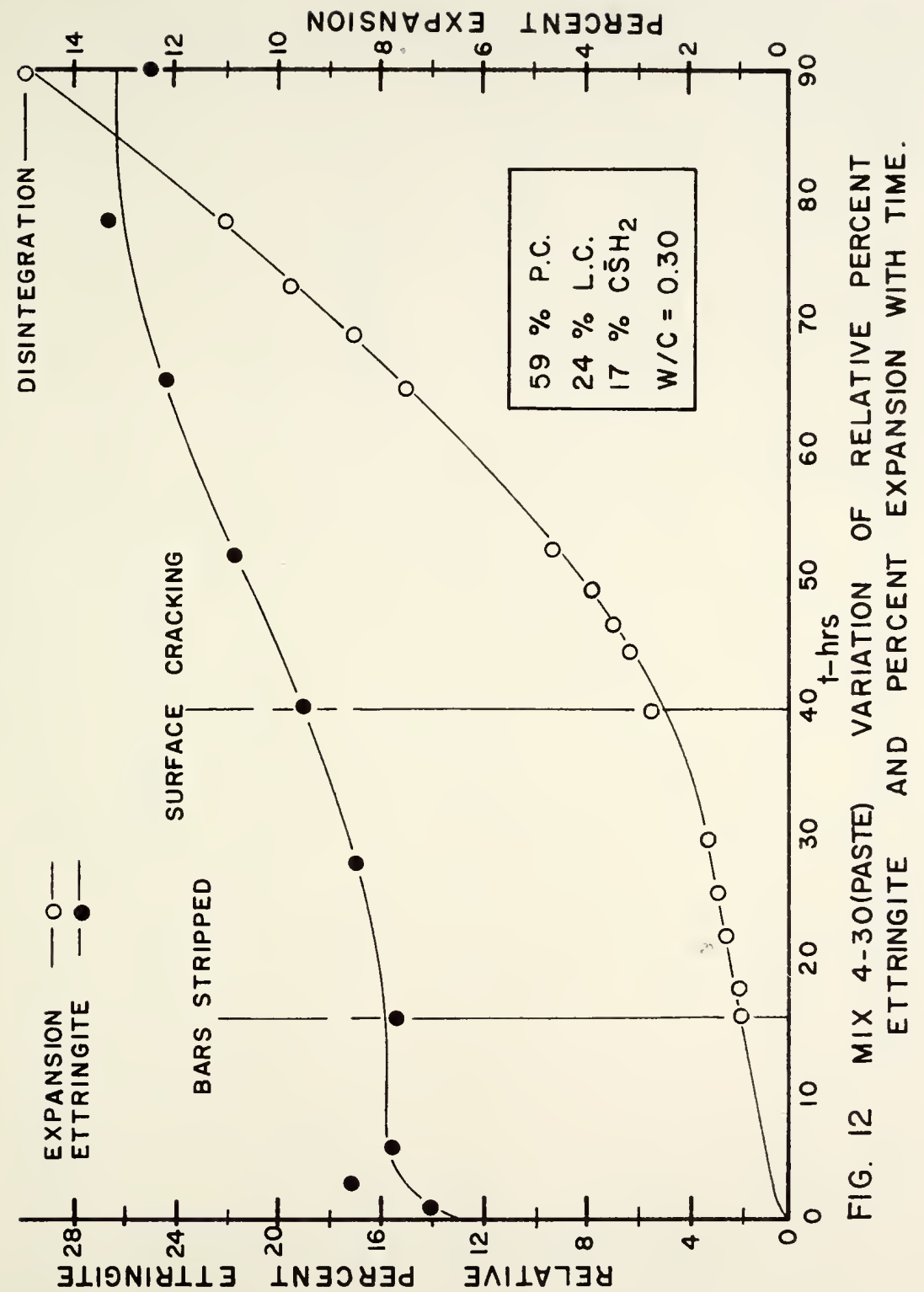




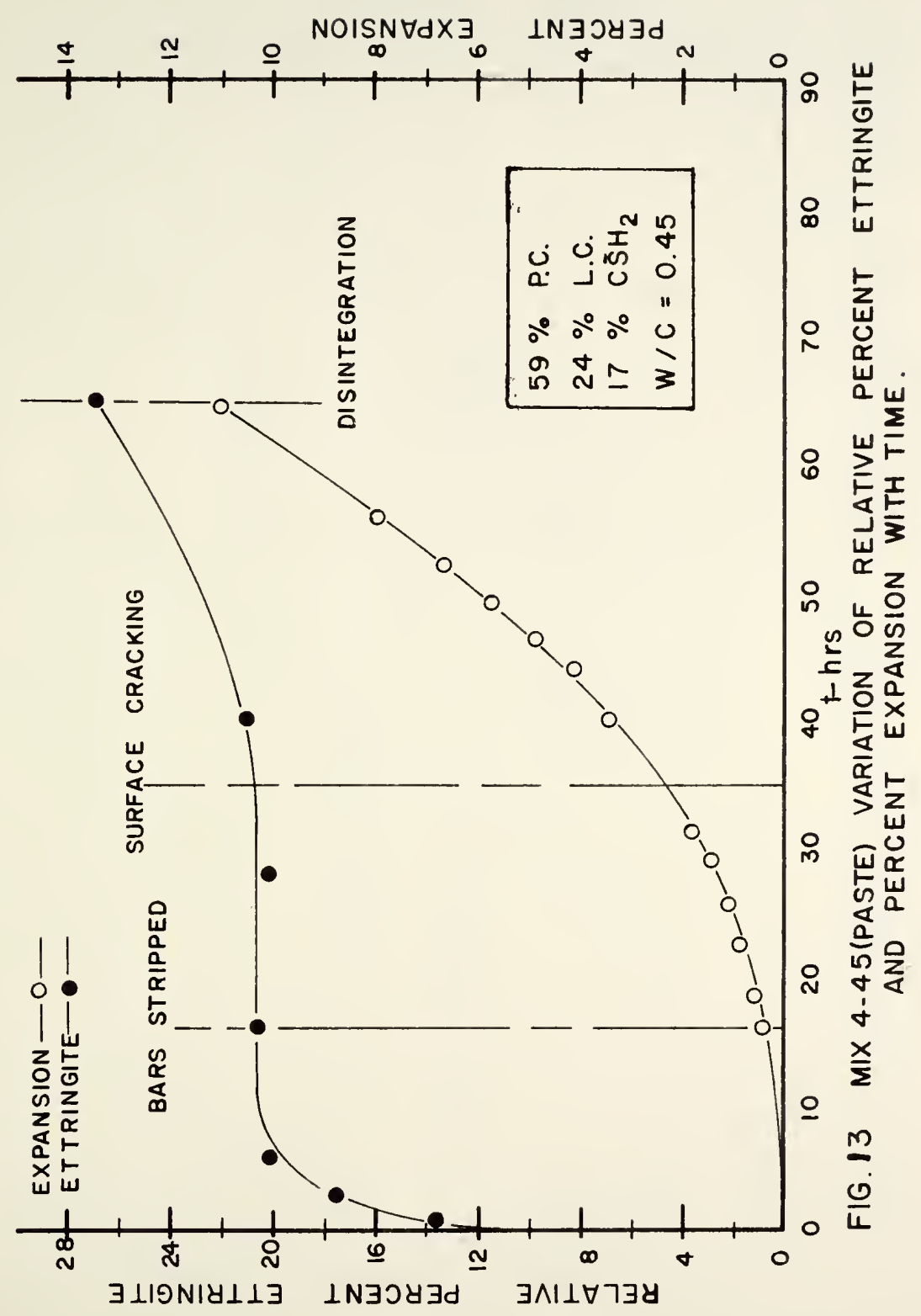




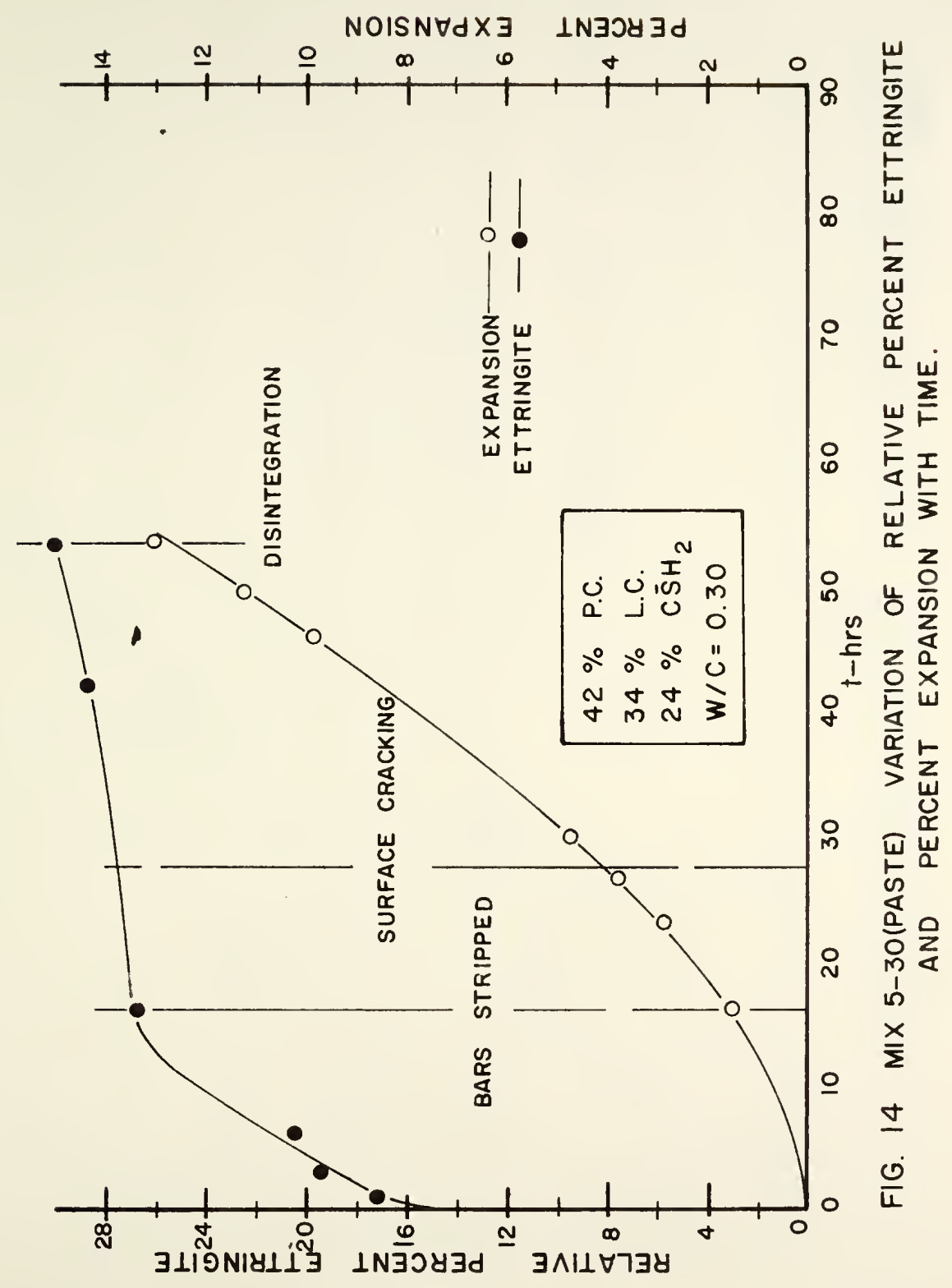




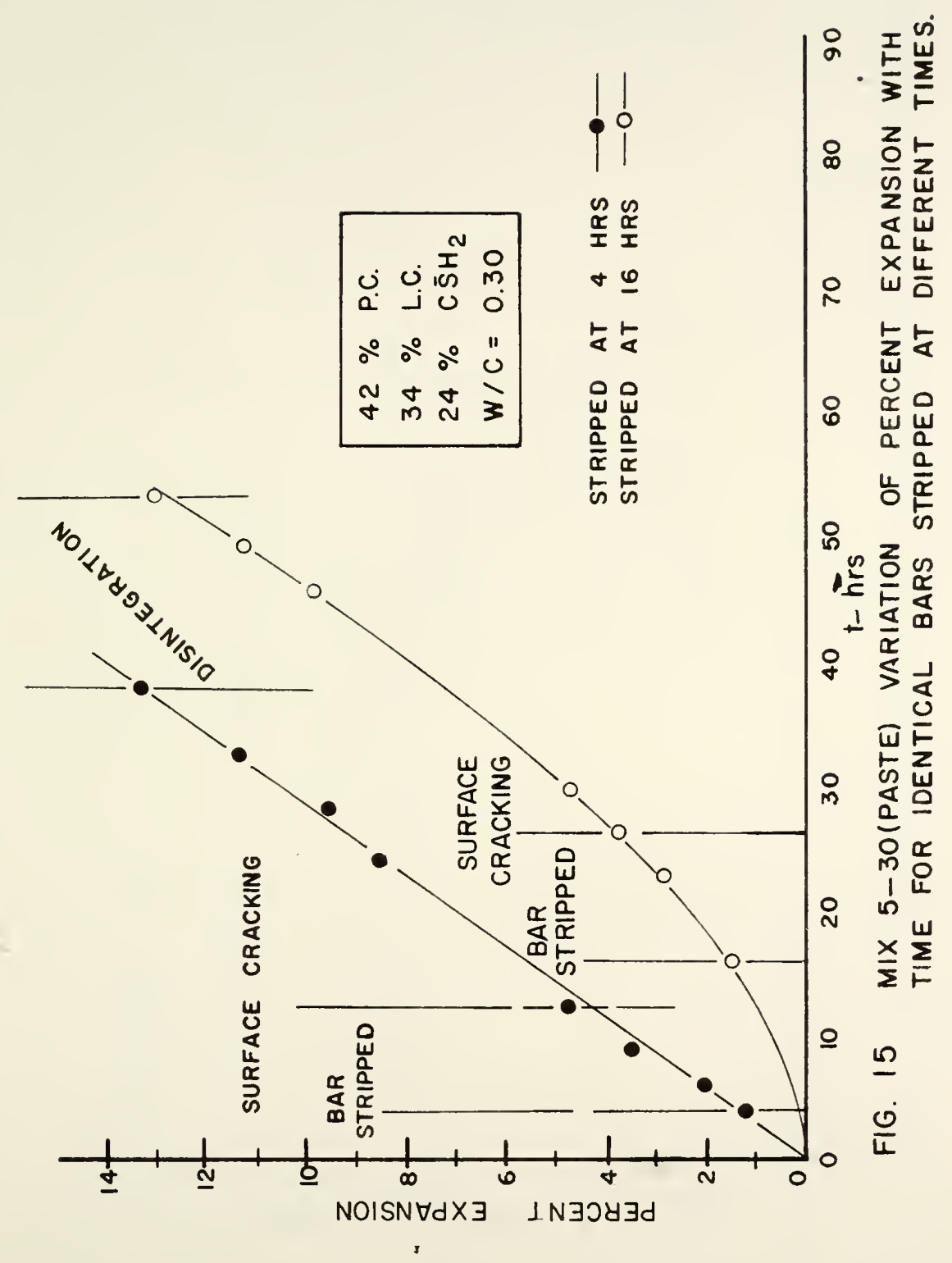




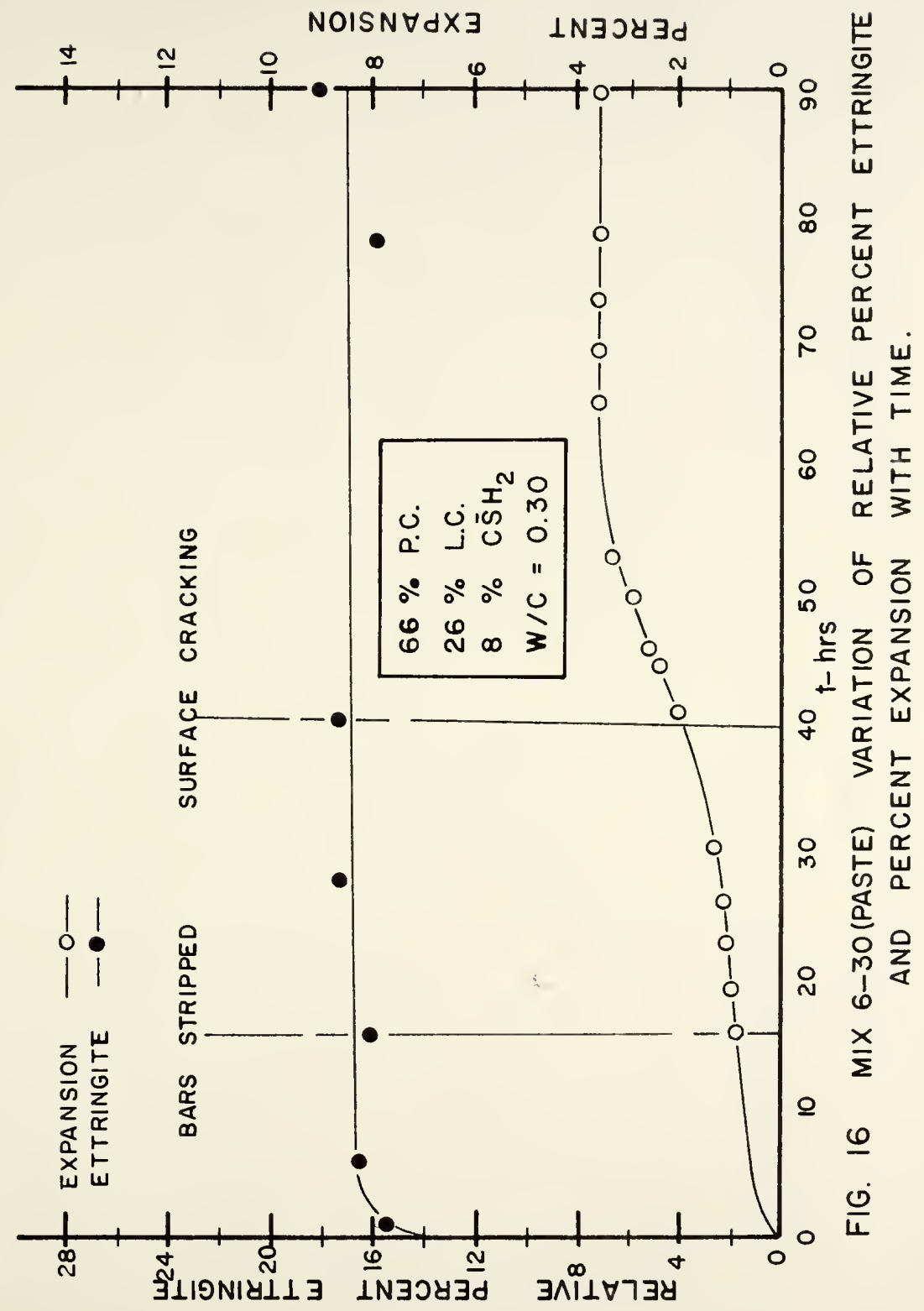




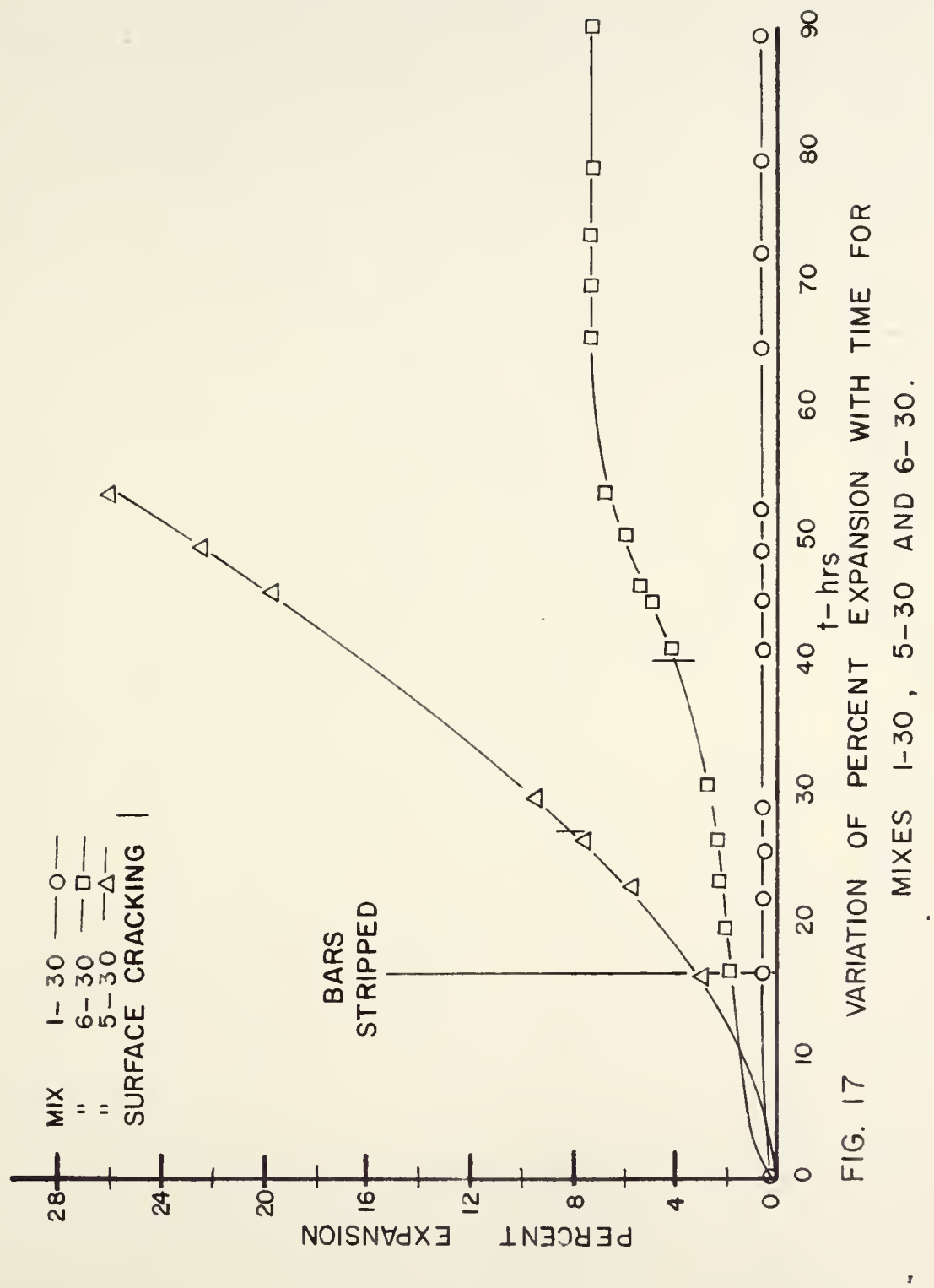




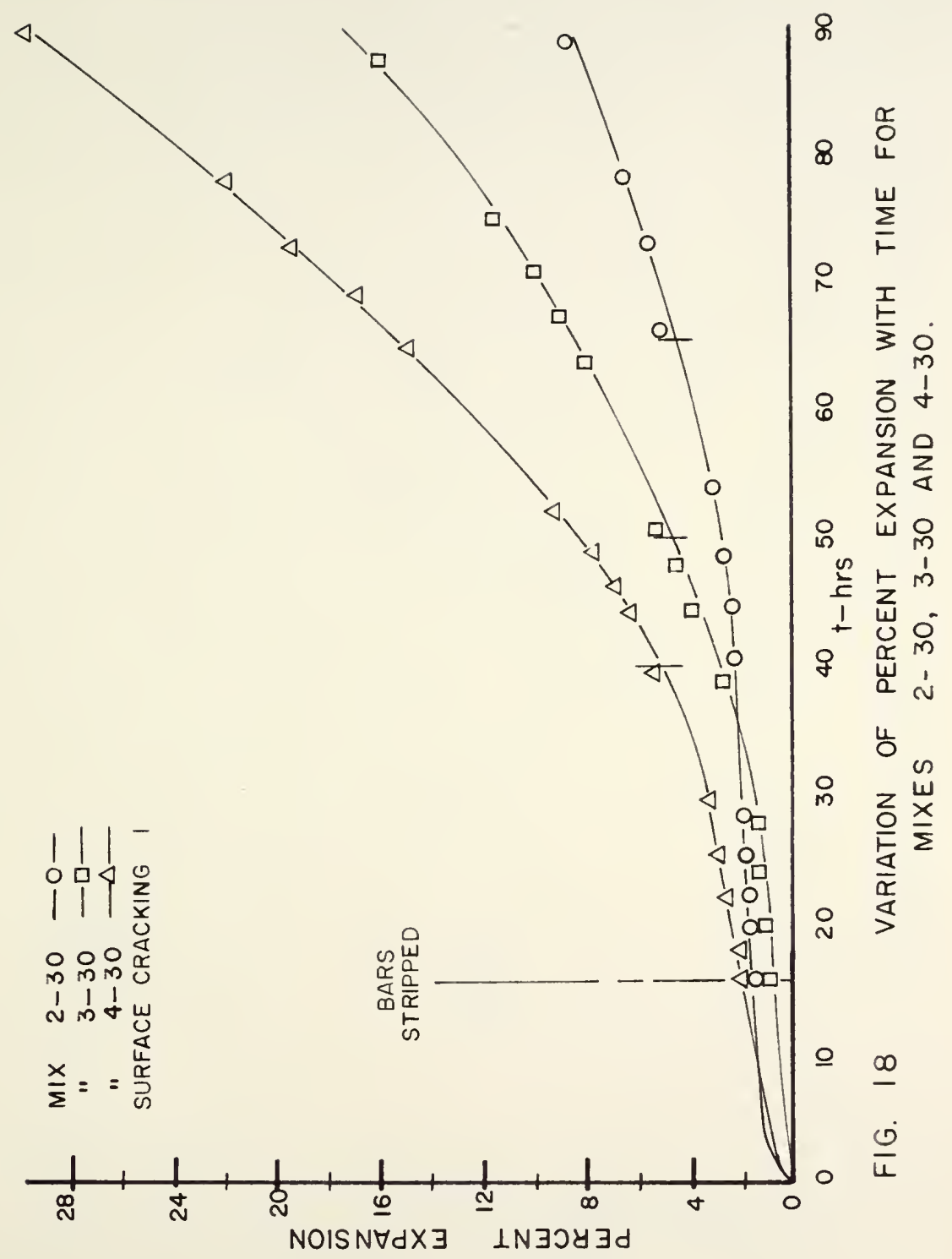




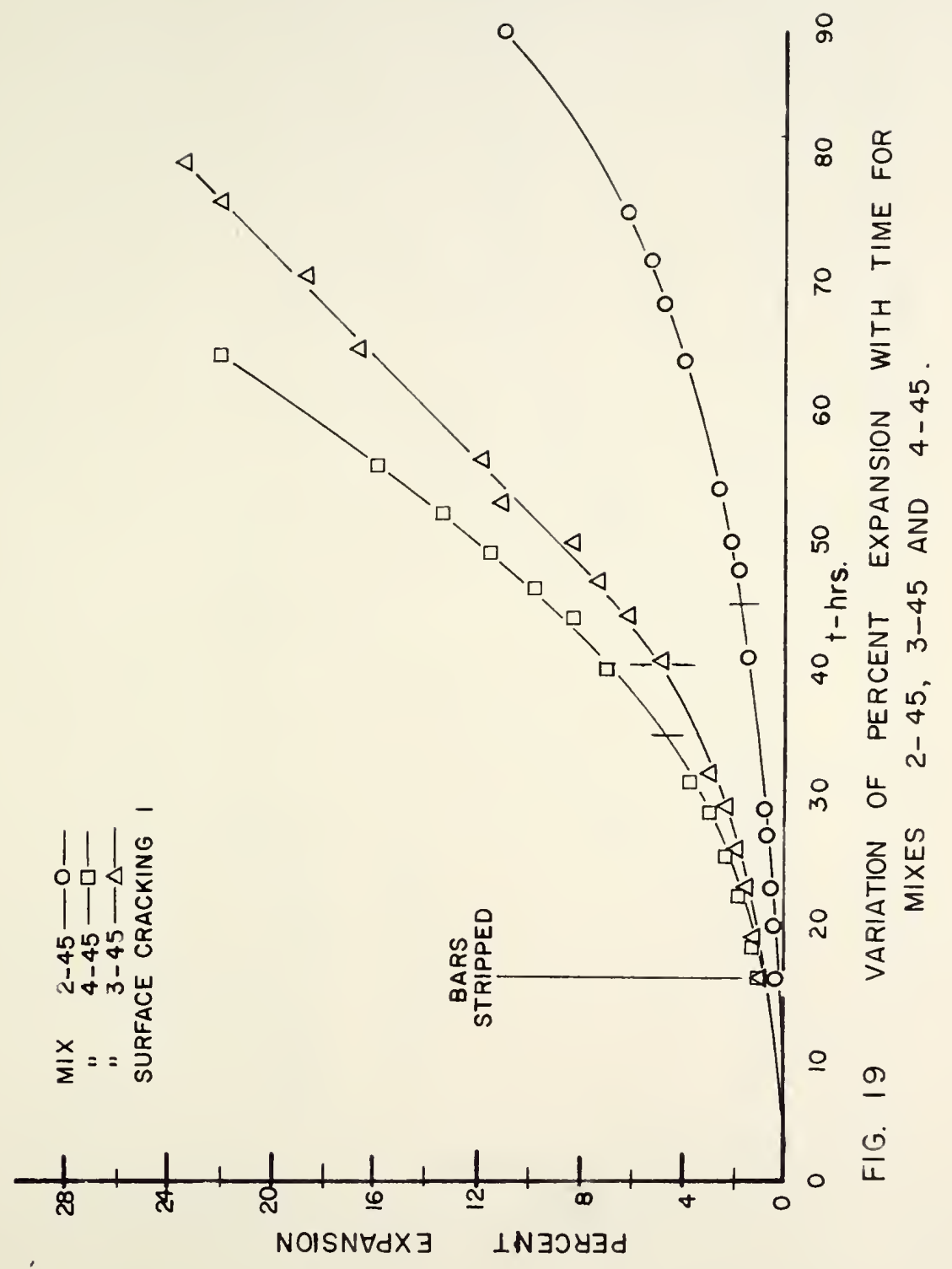




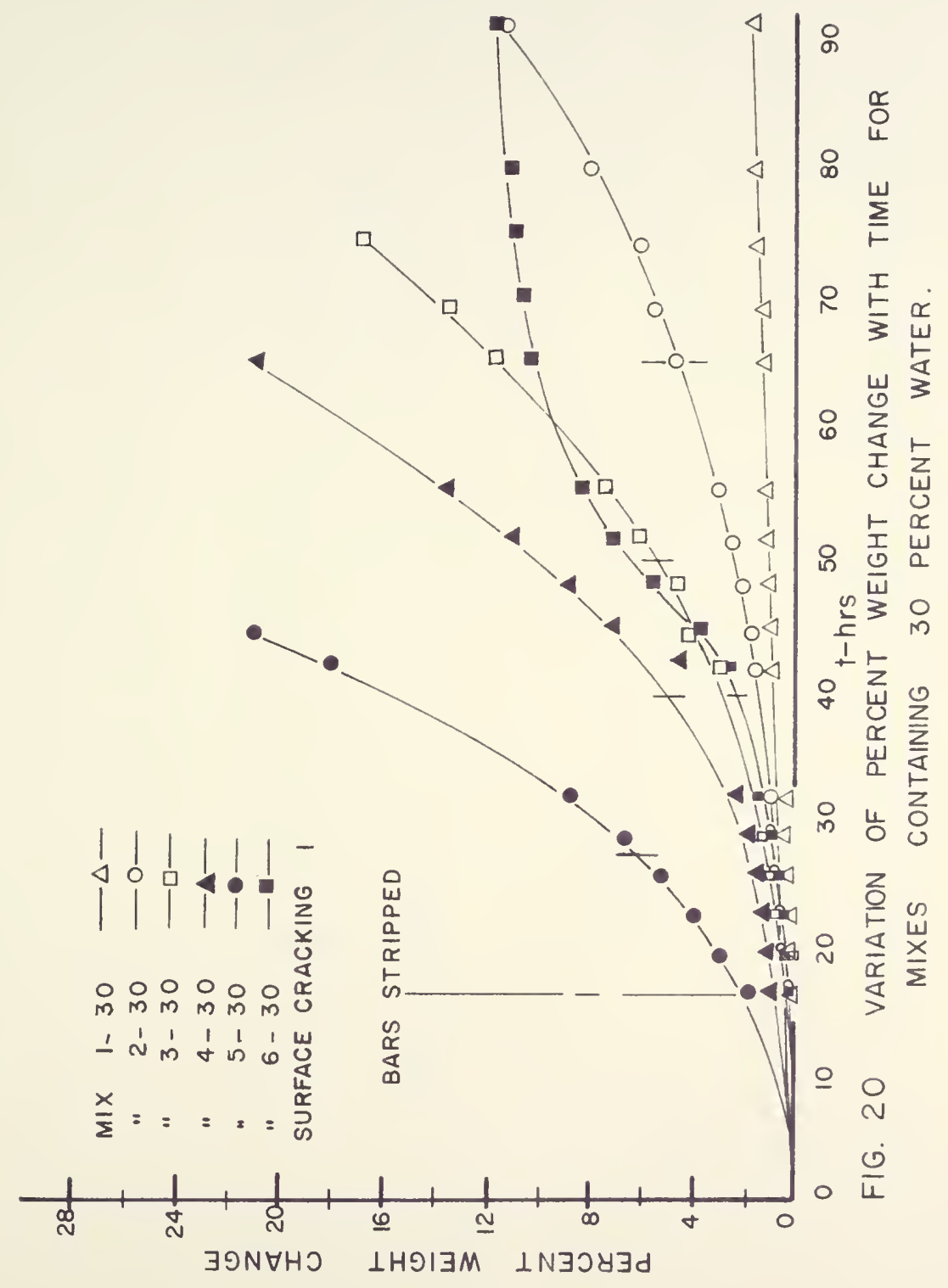




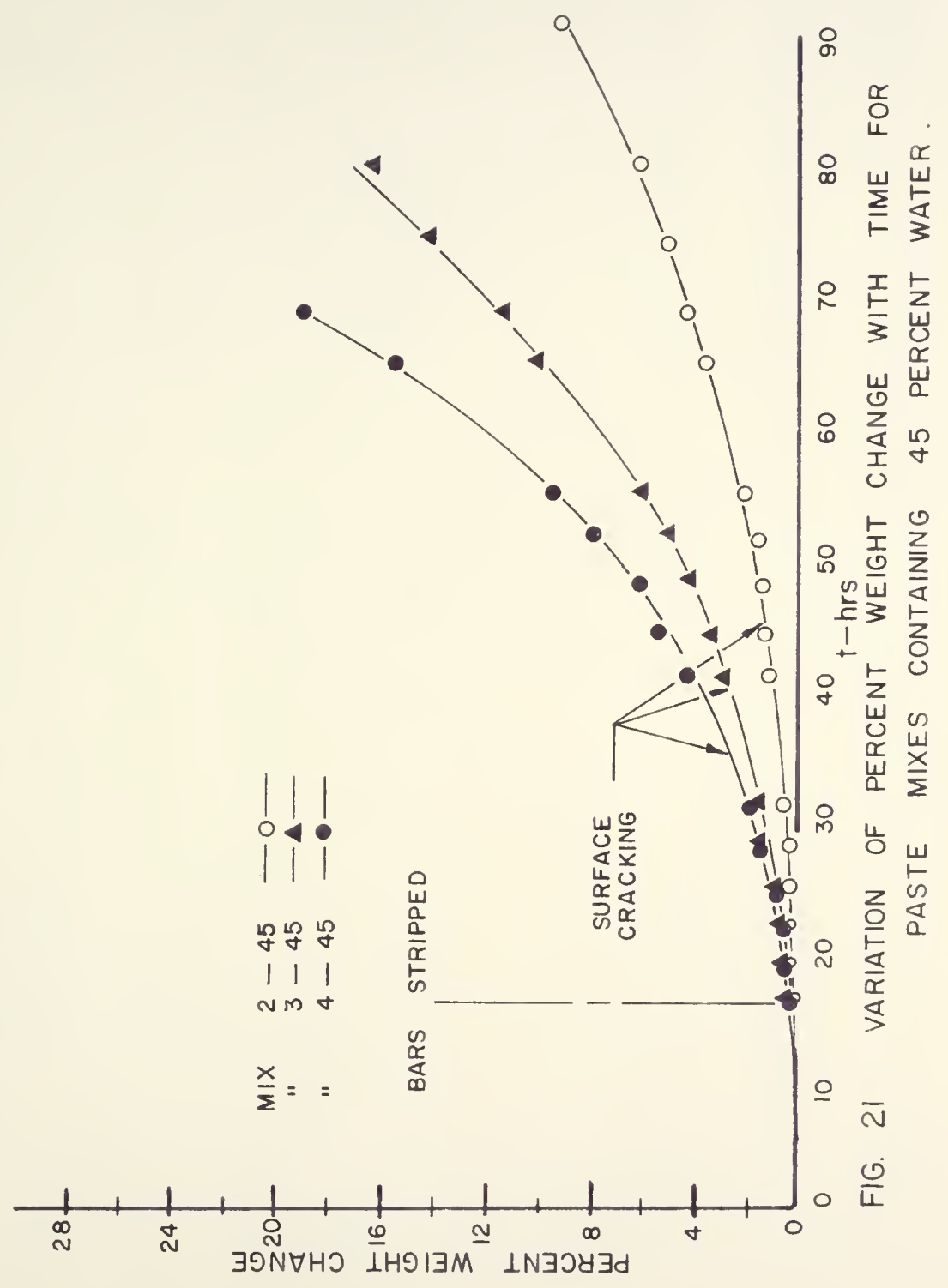




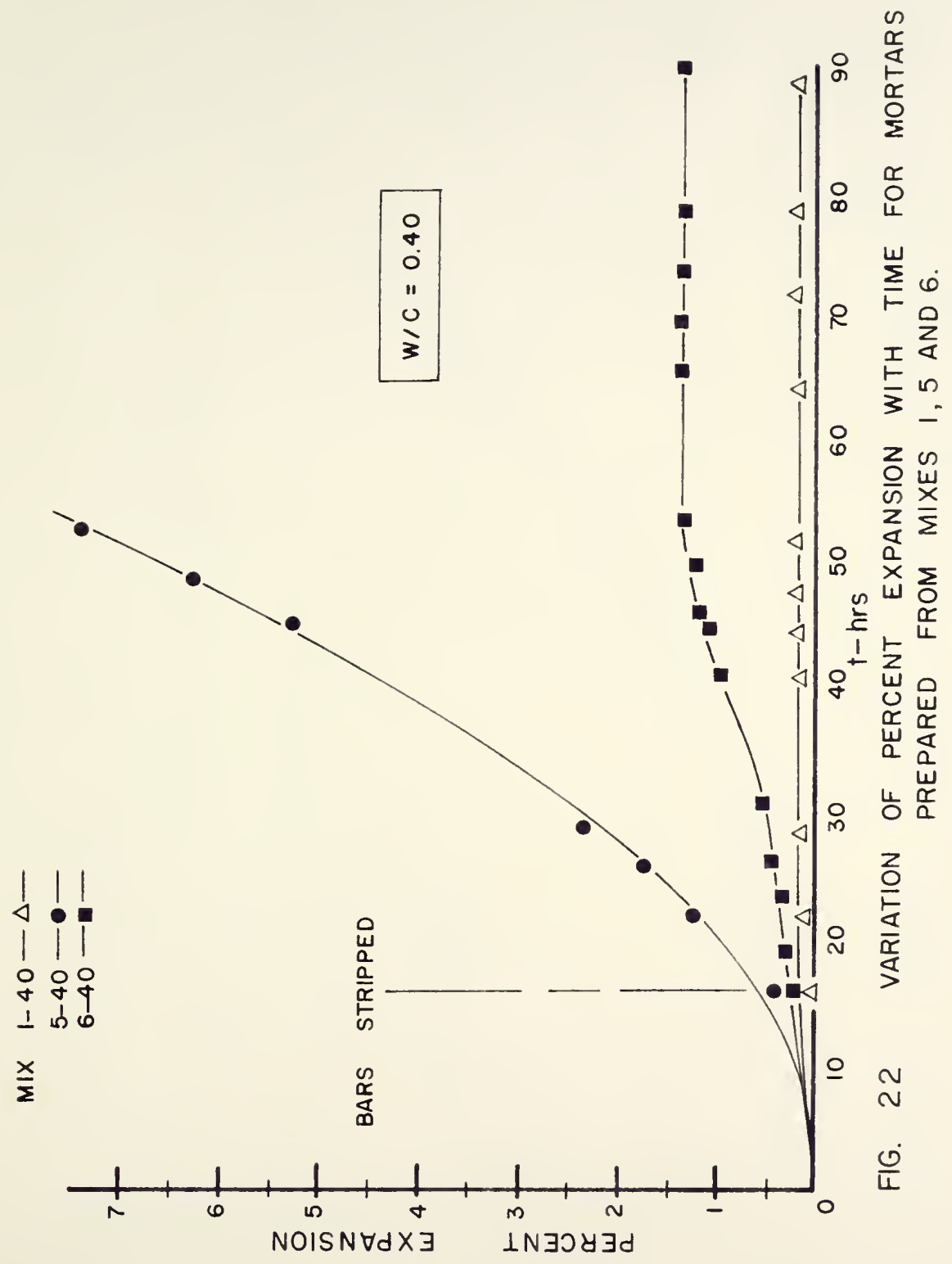




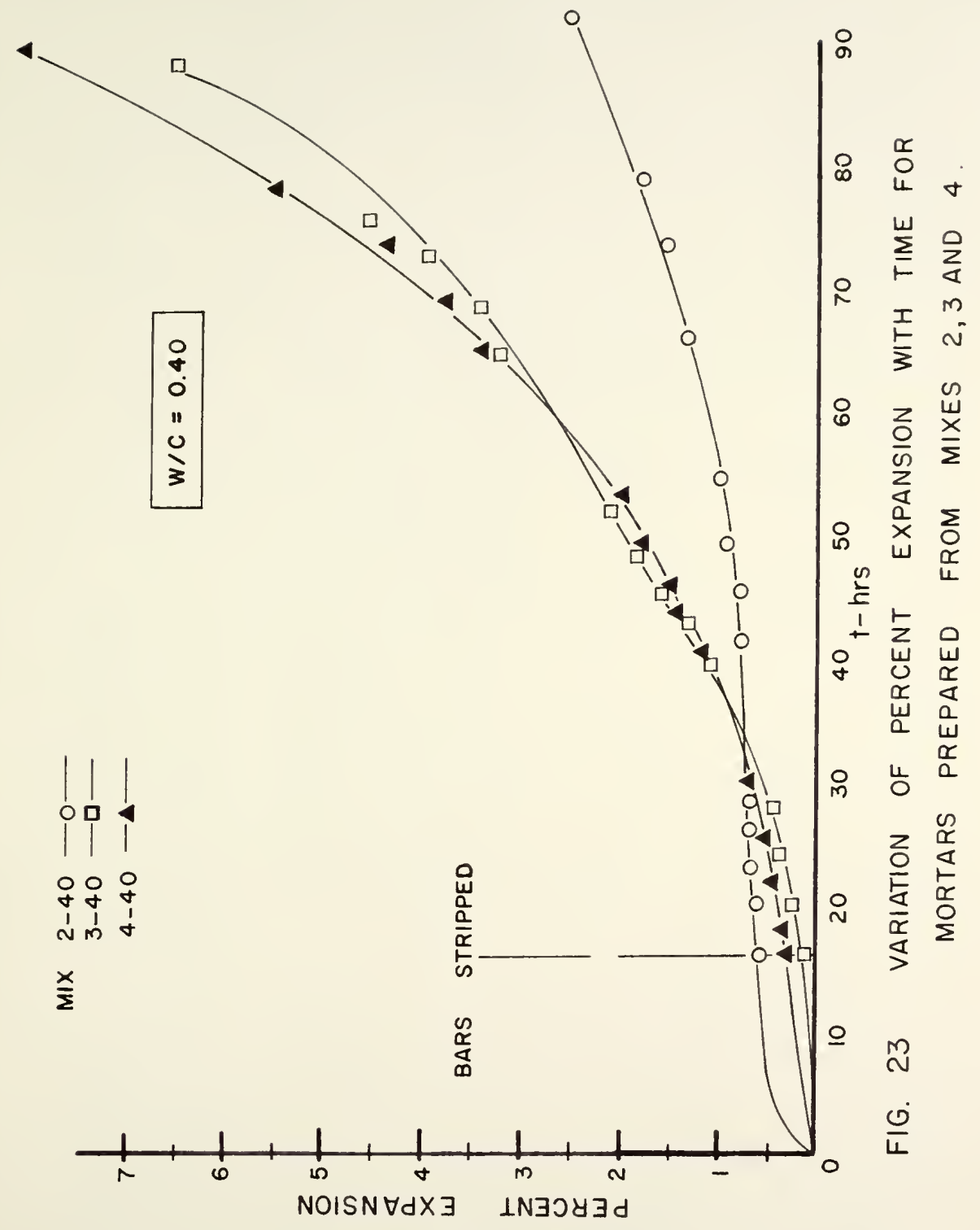




\section{DISCUSSION}

- The purpose of this work was to investigate the relationships between the production of ettringite by a particular type of expansive cements and the dimensional changes of pastes or other mixtures made with these cements. If ettringite is indeed responsible for expansion, there should be some relationships between the amount of ettringite and expansion. This was found to be true, but the relationships are not simple ones, and there are other factors involved. Before these relationships are gone into in detail, there are characteristics of the data that should be pointed out.

With respect to the cement mature compositions, the critical factor with respect to the potential production of ettringite was in all mixtures the amount of gypsum. This statement is based on the fact that the Lumnite $H A C$ was composed mostly of $C A$, which was the conclusion based on X-ray diffraction analysis of the HAC. The potentiality for the production of ettringite varied from a small amount ( $\mathrm{ix}$ No. 1) to a very large anount (Nix No. 5). See Figure 1 and Table 1 .

Mix No. 1 corresponded most closely to a pure Portland cement since the amounts of gypsum and HAC present were only about four percent. Figure 6 shows the production of ettringite to be complete after the first ten hours of hydration. Since the amount of gypsum was:small, it.would be expected that the production of ettringite would be small. The strain data show that there was a very small 
initial expansion during the first few hours of hydration. This expansion had ceased by the time the bars were stripped, and no further volume change was observed during the course of the test. Expansion and ettringite production data for mix No. 2 made with a $\mathrm{w} / \mathrm{c}$ of 0.30 are shown in Figure 7 . Initially there was a rapid production of ettringite followed by a dormant period that lasted until after the molds were stripped from the bars. At this point more ettringite was again produced for a few hours. The rate then decreased and continued at a slower rate during the remainder of the test.

Figure 8 shows expansion and ettringite contents for mix l:o. 2 made with 45 percent water. The ettringite production curve shows an initial rise comparable to the value obtained for the drier mix (Fig. 7). Ettringite increase continued, however, until it ceased after approximately twenty hours of hydration. تttringite production resumed again after about 40 hours of hydration, just before surface cracking of the specimens was noticed.

Comparison of Figures 7 and 8 , shows that ettringite production did not cease before stripping of the molds of the wetter mixture. There was no increase in the amount of ettringite present in the wetter paste after stripping. Between 40 and 65 hours the two curves look much the same. Comparison of the expansion curves from the same two figures shows there was no rapid initial strain in the first few hours for the wetter mix but there was a small one for the drier mix. Strain increase rates were greater for the wetter mix. Surface cracking was noticed about twenty hours earlier for the drier mix. 
In Figure 9 are shown data obtained from $m i x$ No. 3 with a $w / c$ of 0.30 . The ettringite production curve shows a rapid increase during the first hour of hydration. The amount of ettringite increased until about fifteen hours, when production ceased. After about twenty-eight hours there was again a rapid increase in the amount of ettringite present. After approximately forty hours ettringite production slowed and continued at a reduced rate during the remainder of the test. The strain curve shows an initial small linear expansion during the first thirty hours or so of hydration. After this time expansions increased progressively.

Figure 10 shows data obtained for $\operatorname{mix}$ No. 3 with a w/c of 0.45 . The ettringite production curve shows an initial rapid rise. After thirty hours of hydration ettringite production ceased and did not begin again until surface cracking was observed. Production of ettringite again leveled off when disintegration of the paste was nearly complete. Expansion increased progressively until after approximately forty hours of hydration. After this tire the strain rate renained constant until disintegration was complete.

When Figure 10 is compared with Figure 9, it is seen that again there was no leveling off of ettringite production before stripping in the wetter mix, but there was in the drier mix. Surface cracking occurred ten hours earlier for the wetter mix. Also there was no distinct rise in the ettringite production curve of the drier mix at the time of surface crackine.

Figure 12 shows data obtained from bars made with mix lio. 4 at $a \mathrm{w} / \mathrm{c}$ of 0.30 . The ettringite production curve shows an initial 
rapid production that ceased after approximately six hours. Production resumed after stripping of the rolds and continued until disintegration was nearly complete.

Figure 13 shows data for the same mix but with a w/c of 0.45 . There was a large initial production of ettringite that ceased after nine hours of hydration. There was no further increase of ettringite until surface cracking was first noticed. After this time production was progressively greater until disintegration was complete. The strain data show that expansion increased progressively until the bars were destroyed.

Comparison of Figure 13 with Figure 12 shows that the production of ettringite during the first hour leveled off at approximately the same time in both mixes ( 9 hours), but that the amount of ettringite produced during this time was much greater in the wetter mix. Ittringite production in the wetter mix was not affected by stripping while production in the drier mix did not appear to be affected by the onset of surface cracking. The ultimate percentage of ettringite in the two samples was about the same. The ultimate strain was greater for the drier mix. Disintegration and surface cracking occurred earlier in the wetter mix.

Figure 14 shows data obtained from $\operatorname{mix}$ llo. 5 with a w/c of 0.30 . There was a large initial production of ettringite during the first hour or so of hydration. This was followed by a further large production. At stripoing, production of ettringite ceased but soon resumed at a slower, rate until disintegration occurred. The expansion data show an increasing expansion during the life of the bar. 
Mix No. 6 was the only one that did not have a Lumnite cement to gypsum ratio of 1.43 . This mix contained the same amount of Portland cement as did mix No. 3 but had a larger Lumnite HAC and a smaller gypsum content. It can be seen from the ettringite production curve (Fig. 16) that there was a large initial increase during the first few hours of hydration. The production leveled off, and only a very slight change was observed during the remainder of the testing program. The expansion data show that strains increased until. approximately ten hours after surface cracking was observed. Strains slowed until no further expansion was observed during the remainder of the test.

Figures 17-19 show that the expansion rates increased as the original Portland cement contents decreased for all cases where the Lumnite to gypsum ratio was 1.43 . Expansion rates were greater in the wetter mixes than for the corresponding drier mixes.

wel ht change data were obtained from paste bars prepared identically to those used for the other measurements. The bar weight at zero time was obtained by extrapolation from a plot of weight vs. time. The bars were first weighed after they had hydrated for 1ó hours and were stripped from the molds. Figure 20 shows weignt change data for ios. $1-30,2-30,3-30,4-30,5-30$ and $6-30$. The relative weight gain of the bars was larger for those compositions initially lower in Portland cement. Figure 21 shows the weight change data for mixes ios. 2-45, 3-45 and 4-45. Here again, as the initial Portland cement contents were made smaller the relative weight gain of the bars became larger. The anount of wolght increase was less 
for the mixes with a higher water content. The slope of the weight curves increased rapidly after surface cracking was observed.

In all instances, $\mathrm{CSH}_{2}$ was present at the end of the man, as indicated by the X-ray diffraction pattern with the exception of mixtures Nos. 1 and 6 . As can be seen from Figures 6 and 16, these samples had no production of ettringite after the initial amount presumably because the supply of gyosum was exhausted. Gyonsum was present in all stages of ettringite production for all other samples. The leveling out of ettringtte production observed in Figures $6-10$, $12,13,14$, and 16 must therefore be due to some cause other than gypsum exhaustion. One other possible cause was the exhaustion of the water initially present in the mix. Ettrineite has much water of crystallization (nearly 50, by weight). If water is no longer avaiable, production of ettringite will cease regardiess of the availability of other constituents. This seems to have occurred even though the samples were water-cured at all times. During the time the bars were in the molds, water had access only through the snall space at the too. Some water probably did get in, but not enough to fill the great demand. A sample calculation was made, based on a hydration period of a one day since this was the time at which most of the ettringite plateaus occurred. This calculation assumed that 50 percent of the Portland cement had hydrated, $2 / 3$ oi the Lumnite had gone to $\mathrm{CAH}_{10}$, and a non-evaporable water content of 0.2 and a gel water content of $0.15 \mathrm{~g} / \mathrm{g}$ of Portland cement that hydrated. This calculation, although crude, showed that there was not nearly enough water originally present in the mix to form all the ettringite capable of being formed. It also showed that there was not even 
enough water to form the ettringite that was found. This point will be discussed further.

There are characteristic features from all the curves that should be pointed out. Initially there was a very large production of ettringite that was not accompanied by any substantial expansions. The initial expansions observed in some cases were relatively insignificant compared with the expansions that occurred at later times. For this reason, if no other, there is no simple relationship between ettringite and expansion.

This result is also the basis for the assumption that much of the original ettringite production occurred by a "through-solution" as opposed to a "solid-state" mechanisn.

If one assures that the production of ettringite in these particular cenent compositions occurred according to the following stoichiometry:

$$
3 \mathrm{C} \overline{\mathrm{SH}}_{2}+2 \mathrm{CH}+\mathrm{CA}+24 \mathrm{H}=\mathrm{C}_{6} \mathrm{~A}_{3} \bar{S}_{3} \mathrm{H}_{32}
$$

then a sample calculation shows a volume decrease for this reaction. The line, of course, is provided by the hydrating Portland cement. If this reaction is acconodative in the sense of a smaller volume of products than that of reactants, one would expect no expansion of a system undergoing this reaction if it takes place in such a way as to use effectively the space formerly occupied by reactants for the deposition of the oroducts. It is logical to assume that a solution process would so use the space because of the inherent mobility of dissolved species and the consequent ability of such a 
process to deposit products in the pore space available. On the other hand, if the reaction proceeds by an attack on a particular solid comoonent withits conversion to the final product more or less in situ, then such a process might well result in a non-use of available pore space and a resultant expansion because the physical geometry of the reactants would tend to determine that of the products. This question has been examined by Lea (3) and others.

These considerations are the basis for the statement that the large ettringite production in all these samples, which was not accompanied by expansion, points to a "through solution" mechanism for its formation. Even if this conclusion is true, however, the data point to some other action also. This point is discussed later. In spite of the lack of relationships between early ettringite formation and expansion there are relationships between potential ettringite and changes that wore observed in the curves in Figures $6_{-} 10$, 12, 13, 14 and 16. The langer the potential ettrineite, the lareer was the amount forned at any comparable stage of hydration. (It was determined from the calibration curve that the ettringite values were probably accurate to \pm 1 ) It was also observed that the larger amount of potential and indeed actual, ettringite, the larger was the ouserved expansions, expansion rates, weight gain and weight gain rates at any comparable stage. The rates and amounts of expansions and increases in weight were more rapid after surface cracking was observed. It can, therefore, be argued that there is a correlation between ettringite production, expansion and weight gain, but not a direct or simple relationship since there is no obvious relationship 
between early ettringite production, expansion and weight gains.

The importance of w/c ratio in all concrete technology is well knowm. To gain additional information on the effects of water content on these expansive materials mix Nos. 2,3 and 4 were also made with a w/c ratio of 0.45 (Figures 8,10 and 13). :ix :ios. 1, 5 and 6 were not tested with a higher $\mathrm{w} / \mathrm{c}$ ratio.

If the notion that water was the essential ingredient in limiting early ettringite production, more water initially available in the mizes should uring about a larcer initial production of ettringite. This was indeed the case. At any comparable stage of hydration more ettringite was produced in the higher water content mixes. Yixes containing the higher water contents also gave Greater expansions at any given point. Figure 11 shows expansion data for mix :io. , made with three difierent water contents. This figure shows a clear influence of $\mathrm{w} / \mathrm{c}$ ratio on the amount of expansion at any given time. There was also an influence of $\mathrm{v} / \mathrm{c}$ ratio on the veirht gains but in a reverse direction to that of the expansions, although the seneral shape of the curves is the same.

The influence of water on expansion may simply be that more ettrincite was formed and therefore it would be logical to assume that more expansion would be expected. It may also be that higher water contents make the cementing cohesive components physically weaker. "lost of the expansion occurred after surface cracking was observed and was therefore part of a progressive disintegration, although the samples could be handled until much later times. Expansions were far larger than those that would be expected from 
any elastic or creep mechanisms. It must therefore be assumed that micro-cracking occurred before the surface cracking was noticed. This micro-cracking influence was probably more prevalent in the mixes containing 30 percent water since their demand for water was higher. Affinity for water probably was greater for these mixes and it would be expected that cracking may have occurred due to additional ettringite being produced in the outer layers. This progressive cracking would allow water to penetrate deeper into the structure. This phenomenon, if real, was probaily not as inportant in the mixes containing 45 percent water because, even though the amounts of ettringite were higier in all cases and the samples were probably weaker, the ettringite was probably more dispersed throughout the medium and its efiects less localized. The increased veight gain ooserved in the lower water mixes was probably due to water filling these micro-cracks as well as to water corbining chemically to form ettrincite.

Gereral trends are observable between the 30 and 45 percent water mixes (Fisures $6-10,12,13,14$ and 16). The amount of ettringite tended to increase after stripoing in the mixes with $\mathrm{w} / \mathrm{c}=0.30$. and its production was not changed by visible surface cracking. Conversely, in the mixes of $\mathrm{w} / \mathrm{c}=0.45$, there was no change in the amount of ettringite on mold stripping but its production resumed again about when surface cracking was noticed.

When the molds were stripped a larger area was avajlable for water ingress and ettringite was probably produced again at least in the surface layers. This is what seems to have happened in 2-30, 
4-30 and 5-30 but mix No. 3 was a little different. Although the data were rechecked, the ettringite production in mix 3-30 did not increase as soon as stripping occurred, but there was a time lag. In the case of the mixes containing 45 percent water it would be logical to assume that they were less sensitive to stripping because the water initially available is more adequate to sustain ettringite production. These ettringite production curves also leveled out, however, which fact indicates the exdrustion. of water to be not the only factor operating. Other factors involved may be coatings of the reactant particles and diffusion of water through such barriers. Such a mechanism is the one invoked to exflain the retarding action of gyosun in ordinary cerent by the coating of $0, A$ grains bj ettringite. Where is no reason to think it is not partially operative in other sinilar systems.

In spite of relatively large differences in potential ettrinoite and water contents, surface cracking took place at about 2 percent linear strain in most instances. Surface crackins occurred at a later time in every case for mixes made with 30 percent water and did not appear to be accompanied by increases ir ettringite. It may be that surface cracking did increase the ettringite production but that this increase is part of the seneral increase that began after stripping of the drier mixes.

As was previously noted, initial large ettringite production was not accompanied by volume change and probably not by a weight change. Weight changes occurring before 16 hours of hydration'are questionable since the weight at zero time was extrapoluted from a 
plot of weight vs. tine. In certain instances there did seem inftially to be a small jump in expansion, but this expansion was small relative to the large increases that occurred at later times. Initial expansions could perhaps have been due to experimental error. This would be possible if the "float" was initially set too low and rebounding upward or if the paste swelled up around the float without moving it. ither of these errors is unlikely since two bars were used for each expansion test. Also, no swelling was observed around the "flozt" and the pastes stiffened too quickly for it to occur.

It appears from Fisure 6 that ettringite, in arounts up to about 10 percent, can form with ro expansion occurring. If the bar tended to expand, it was contained elastically by the large Portland cement content present. The sample from mix llo. 1 was firm, stable, and did not disintegrate. The converse is also ojserved in mir. No. 6 (Fig. 16) where an appreciable expansion was observed at a time when no additional ettrincite was produced beyond the initial amount. In this mix, however, the ettringite produced was half again as much as that in mix :o. 1 and the Portland cement content was less. Both these factors would tend to contribute to a tendency toward a volume change. The weight gain curve shows the same general shape as the volume chance curve. Expansions did not occur until long after ettringite production had ceased and the bars did not disintecrate. The observed expansion must therefore have been the result of a longterm process since, at the tine of the expansions, no ettringite was being produced. The samples acted as if they had some sort of a coiled "spring" inside it. This "spring" caused the volume to 
increase until after surface cracking occurred. When the "spring" became fully extended expansion ceased. The nature of the "spring" is largely speculative but deformations of the same nature as creep could be due to stored elastic stresses inherent to ettringite. It would be necessary, however, to postulate larger stresses than are normally stored residually in elastic materials.

This "spring" mechanism could also be brought about by a change in the water of hydration of ettringite. It has been observed that ettringite can exist with less than 32 moles of water, dopending on the temperature (35). It may be that ettringite produced when little water is available for hydration may form in a "dry" phase. It is possible to have ettringite with 20 moles of water and still observe no change in the X-ray pattern (35). It is therefore possible that the initially formed ettringite may have contained fewer than 32 moles of water. Part of the volume and weight increases may then be due to the ettringite absorbing additional water. This explanation is supported some by the calculations that showed that there was not enough water initially available in the 30 percent water mixes to form the ettringite that did indeed form if 32 moles of water per mole of ettringite were required. If some such efiects operated in mix No. 6 , there is no rossor. to belisve that they did not operate in other mixes showing expansion and secondary ettringite production. Figure 15 shows expansion data for two bars made from mix 1:0. 5-30 but stripped at 4 and 16 hours respectively. These data show that expansion increased much more rapidly for the bar stripped at 4 hours. This increase was, furthermore, at a corstant rate. Ultimate expansion 
was approximately the same for the two bars, although the value was reached ten hours later for the bar that was stripped after 16 hours of hydration. These data are consistent with the "spring" mechanism since it means that the spring constant was decreased by keeping the bars in the molds longer. It also means that the "spring" was the same "size" in the two bars since the expansions were the same at disintegration.

Iortar bars were prepared for each of the six test mixtures. A water to fine material ratio of 0.40 was used for all bars. Figures 22 and 23 show that the expansion strain rates increased as the Portland cement contents originally present in the mix decreased. The mortar expansion curves also showed the same general shape as the paste curves except that there was less expansion due to restraint by the aggregate. This is the same effect observed in

- other mortar and concrete systems.

Chatterji and Jeffery have postulated that the mechanism responsible for expansion due to sulfate attack on cementatious systems, where the sulfate ions are brought in from outside the system, is the conversion of $\mathrm{C}_{4} \mathrm{All}_{13}$ to low calcium sulfoaluminate which in turn goes to ettringite (2i). Although the system investigated in this paper was different from these, no $\mathrm{C}_{4} \mathrm{AH}_{13}$ or monosuliate was found in the samples at any time and the data that were obtained does not support this mechanism. 


\section{ST:ATAY}

Expansive cements containing proportions of Portland cement, high-alumina cement, and gypsum were prepared. Pastes were made with these mixtures at two different water contents. The pastes were molded into small cylinders, which were kept imnersed in water. These cylinders were tested to determine their linear expansion, change in weight, and content of tricalcium aluminate trisulfate (ettringite) at various times. The ettringite was determined by quantitative X-ray diffraction.

The amount of ettringite, in general, increased very rapidy in the first few hours and then became more or less constant for a sirilar period. If the mixture contained sufficient gypsur the ettringite contents increased further after either the strippine of the mold or the onset of visible surface cracking.

The expansion was negligible at first and gradually became progressively greater to the point of disintegration of the sample. Visible surface cracking occurred at about two percent linear expansion, but the specimen remained intact to about ten percent expansion.

The weight gain was of the same nature and relative extent as the expansion.

The effects of larger aluminous cement and gypsum contents (more "potential" ettringite) and smaller Portland cement contents 
of the original mixtures were:

1. The amount of ettringite formed at any comparable stage in the process was greater.

2. The expansion at any comparable stage was greater, as was the weight gain.

3. The rate of expansion and weight gain in the later stages was greater.

4. If the eypsum content was so small that it was exhausted early in the orocess, no further ettringite was formed.

The effects of higher water contents of the pastes were:

1. Yore ettringite was forred at any comoarable stage in the process.

2. Nore expansion occurred at any comparable stage.

- Less weight Eain occurred at any comparable stage.

4. The resumption of production of ettringite after the initial large production and its cessation was related to the onset of surface cracking in the higher water content samples and to stripping of the molds in the lower.

The relationsips between the production of ettringite and expansion were:

1. The initial very large production of ettringite was not accompanied by an expansion of any magnitude compared with later changes.

2. A large amount of ettringite was formed in some samples with no resultant volume change at any time. 
3. Expansion occurred in sone samples long after the initial ettringite was formed and at a time when no further ettrineite was being produced.

No tricalcium aluninate monosulfate or $\mathrm{C}_{4} \mathrm{All}_{13}$ was observed in X-ray diffraction patterns.

Earlier stripoin of molds caused earlier and greater expansion. 


\section{CONCLUSIONS}

Based on the samples tested and the tests performed the following conclusions seem reasonable. They obviously apply only to the particular composition of expansive cements used in this study and not necessarily to other compositions or systems.

1. Relatively large amounts of ettringite in cenentitious systems can be determined with reasonable accuracy by X-ray diffraction procedures.

2. Results of experinents with highly expansive coments depend to a large degree on experimental details of specimen preparation and treatment.

3. Greater exoansion of these cement systems is associated with larger amounts of potential ettringite in the mixture, greater amounts of ettringite actually formed, and with greater water contents. The relationships between these factors are not simple.

4. A large amount of ettringite in these cements forms very rapidly and in a way that does not cause concurrent expansion. An accomodative process, such as a through-solution mechanism, is indicated. Some of the initially-formed ettringite, orobably a minor portion, does have an expansive potential and brings about expansion at relatively long times after its formation.

5. Exhaustion of water is probably an important factor in Imiting production of ettringite. It is not, however, the only, factor so operating. 
6. Ingress of water to cause formation of more ettringite is a principal cause of expansion of these cements. This ingress can be facilitated by removal of molds or partial cracking of the sample. 
BIEIIOCRAPHY 
1. Gonnerman, H. $\vec{I}_{0}$, Wiliam Lerch and Thomas M. Whiteside, "Investigations of the Hydration Expansion Characteristics of Portland Cement," Portland Cement Assoc.. Res. Deot. Bull. 45. Develon Dep. Buld. 1-5, (1953).

2. Ref. 25, p. 10-12.

3. Ref. 26, p. 457.

4. Vonfore, G. E., "Properties of Expansive Cerent Viade with Portland Cement, Gypsum, and Calcium Aluminate Cement," J. Portland Cement Assoc., Res. Dev. Lab, E, :0. 2, 2 (1964).

5. Vikhailov, V. V., "Stressing Cement and the liechanism of SelfStressing Concrete Regulation," Proc. 4th Intern. Symo. Chem. Cement (Nashington), 927 (1960).

5. Lafuna, H.. "Expansive Cements," Proc. 3rd Intern. Symp. Dhem. Sement (London), 581 (1952).

7. Klein, A. and G. E. Troxell, "Studies of Calcium Sulioaluminate Admixtures for Expansive Cements," Am. Soc. Testing Mater., Proc. 58. $986(1958)$.

8. Klein, Alexander, Tsevi Karby and Milos Polivka. "Properties of an Expansive Cement for Cement for Chemical Prestressing," Am. Concrete Inst. Proc. 58, 59 (1961).

9. Lin, T. Y. and A. Kein, "Chemical Prestressing of Concrete Elements Using Expanding Cements," Am. Concrete Inst. Proc. 60, 1187 (1963).

10. Kozielski, Waclaw, "High-Expansive Cement in USSR," Cement-ivano= Gins, 2. No. 18, 95 (1953); C.A. 48, 1647 (1954).

11. Skramtaev, B. G., and I. Kravihenko, "Gypsum-ilumina Expanding Cement," Stroitel-Naterialy 2, No. 3, 10 (1956); C.A. 50, $10365(1956)$.

12. Budnikov, P. P. and Z. S. Kosyreva, "Sxpanding Portland Cement Without Formation of Sulfoaluminate," Tsement 8, No. 4, 11 (1952); C.A. 42 , 28 ? (1953). 
13. Ginzburg, Ts. G. and O. V. Kuntsevick, "Investigations of Expanding Cements and Their Various Conditions of Setting," Izvest. Vsesoyuz. Nauch-Issledovatel. Inst. Gidrotekh, 51 , 198 (1954): C.A. 51, 1577 (1957).

14. Mchedlov-Petrosyan, O. P., and L. G. Filatov, "An Expanding Cement for Hydro-Technical Construction," Gidrotekhn Storvit. 22, No. 5. 30 (1962); C.A. 57, 4327 (1962).

15. Budnikov, P. P., "Expanding Cement," U.S.S.R. Patent 69, (Nov. 30, 1947); C.A. 44. $302(1950)$.

16. Ref. 33, p. 300-303.

17. Ref. 26, p. 198-199.

18. "Tentative Recommended Practice For Dealing With Outlying Observations," (ASTM Designation: $178-61 \mathrm{~T}$ ), Am. Soc. Testing Kater., ASTM Book of Stds., Part 30, p. $512(\overline{1964) .}$

19. Dean, R. B. and A. J. Dixon, "Simplified Statics For Small Numbers," Anal. Chem. 23, 636 (1951).

20. Copeland, I. E. and Robert H. Bragg, "Quantitative X-Ray Diffraction Analysis," Anal. Chem. 30, 196 (1958).

21. Chatterji, S. and J. Jeffery, "A New Hypothesis of Sulphate Expansion," Mag. Concrete Res. 15, No. 44. 83 (1963).

\section{General References}

22. Halstead, P. .. and A. E. Moore, "The Composition and Crystallography of an Anhydrous Calcium Aluminosulphate Occurring in Expanding Cement," J. ADpl. Chem. 12, 413 (1962).

23. Eltel, i., "Recent Investigations of the System Lime-AluminaCalcium Sulfate-Nater and its Importance in Building Research Problems," I. Amer. Concrete Inst. 28, 679 (1957).

24. Lossier, H., "The Uses of Expanding Cement Concrete," Concrete and Construction Eng. 42, No. 1, 16 (1947).

25. Robson, T. D., "High-Alumina Cements and Concrete," 263 pp., John Wiley and Sons, New York, 1962.

26. Lea, F. M., and C. H. Desch, "The Chemistry of Jement and Concrete," 2nd ed., 637 pp.., St. Martin's Press, New York, 1956. 
27. Orchard, D. F., "Concrete Technology," Vol. I, p..66-74, , John Wiley and Sons, New York, 1962.

28. Halstead, P. E., "Expanding and Stressing Cements," in "The Chemistry of Cements," by 7. . . W. Taylor, Vol. II, p. 87-98, Academic Press, New York, 1962.

29. Buttler, F. G., L. S. Dent Glasser and H. F. W. Taylor, "Studies on $4 \mathrm{CaO} \cdot \mathrm{Al}_{2} \mathrm{O}_{3} \cdot 13 \mathrm{H}_{2}$ and the Related Natural kineral Hydrocalumite," J. Am. Ceram. Soc. 42,122 (1959).

30. Majumdar. A. J. and Rustum Roy, "The System $\mathrm{CaO} \cdot \mathrm{Al}_{2} \mathrm{O}_{3} \cdot \mathrm{H}_{2} \mathrm{O}$, J. Am. Ceram. Soc. 32,434 (1956).

31. Bogue, R. H., "The Chemistry of Portland Cement," 2nd. ed., p. 29-30, Reinhold Publishing Corporation, liew York, 1955.

32. Kelly, Roger, "Solid-Liquid Reactions," Can. J. Chem. 38. $1209(1960)$.

33. Kug, Harold F. and Leroy Z. Alexander, "X-Pay Diffraction Procedures," 716 pp., john viley and Sons, New York 1954.

34. "ilks, S. S., "Ilementary Statistical Analysis," 284 pp.., Princeton University Press, Princeton, New Jersey, 1961.

35. Berman, H. A. and I. S. Newnan, "Heat of Formation of Calcium. Trisulfoaluminate at $25^{\circ} \mathrm{C}, "$ Froc. 4 th Intern. Symp. Chem. Cement (.ashington), 247 (1960).

36. Heller, L. and IS. Ben-yair, "Effect of Sulphate Solutions on Normal and Sulphate-Resisting Portland Cement," J. Apol. Chem. 14. 20 (196́4). 
APESEDIX A

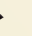


APPEIDIX A

Chemical Analysis of Haterials

A. Type I Portland Cement (317)

$$
\begin{array}{lc}
\mathrm{SiO}_{2} & 21.76 \text { percent } \\
\mathrm{Al}_{2} \mathrm{O}_{3} & 5.41 \\
\mathrm{Fe}_{2} \mathrm{O}_{3} & 1.97 \\
\mathrm{CaO} & 65.30 \\
\mathrm{MEO} & 1.11 \\
\mathrm{SO}_{3} & 2.43 \\
\text { Loss } & 1.78 \\
\text { Total } & 99.66 \\
\text { Free Lime } & 0.72 \\
\text { Insol. Res. } & 0.27 \\
&
\end{array}
$$

$\begin{array}{ll}\mathrm{C}_{3} \mathrm{~S} & 51.20 \\ \mathrm{C}_{2} \mathrm{~S} & 23.83 \\ \mathrm{C}_{3} \mathrm{~A}\left(\mathrm{C}_{2} \mathrm{~F}\right) & 11.00 \\ \mathrm{C}_{4} \mathrm{AF} & 5.99 \\ \mathrm{CSH}_{2} & 5.23 \\ \mathrm{Iia}_{2} \mathrm{O} & 0.08 \\ \mathrm{~K}_{2} \mathrm{O} & 0.46 \\ \text { Total Alkalies } & \\ (\text { as lla } \mathrm{O}) & 0.38\end{array}$


B. Luminite Cement

$\begin{array}{ll}\mathrm{SiO}_{2} & 10.55 \text { percent } \\ \mathrm{Fe}_{22} \mathrm{O}_{3} \& \mathrm{FeO} & 10.25 \\ \mathrm{Al}_{2} \mathrm{O}_{3} & 41.02 \\ \mathrm{C} 2 \mathrm{O} & 35.60 \\ \mathrm{MEO} & 1.89 \\ \text { Total } & 99.31\end{array}$

Compound Composition (Calculated)
\[ \begin{array}{cc}{ }^{2} \text { AS } & 38.5 \\ \text { CF } & 13.9 \\ \text { CA } & 47.6\end{array} \]


